
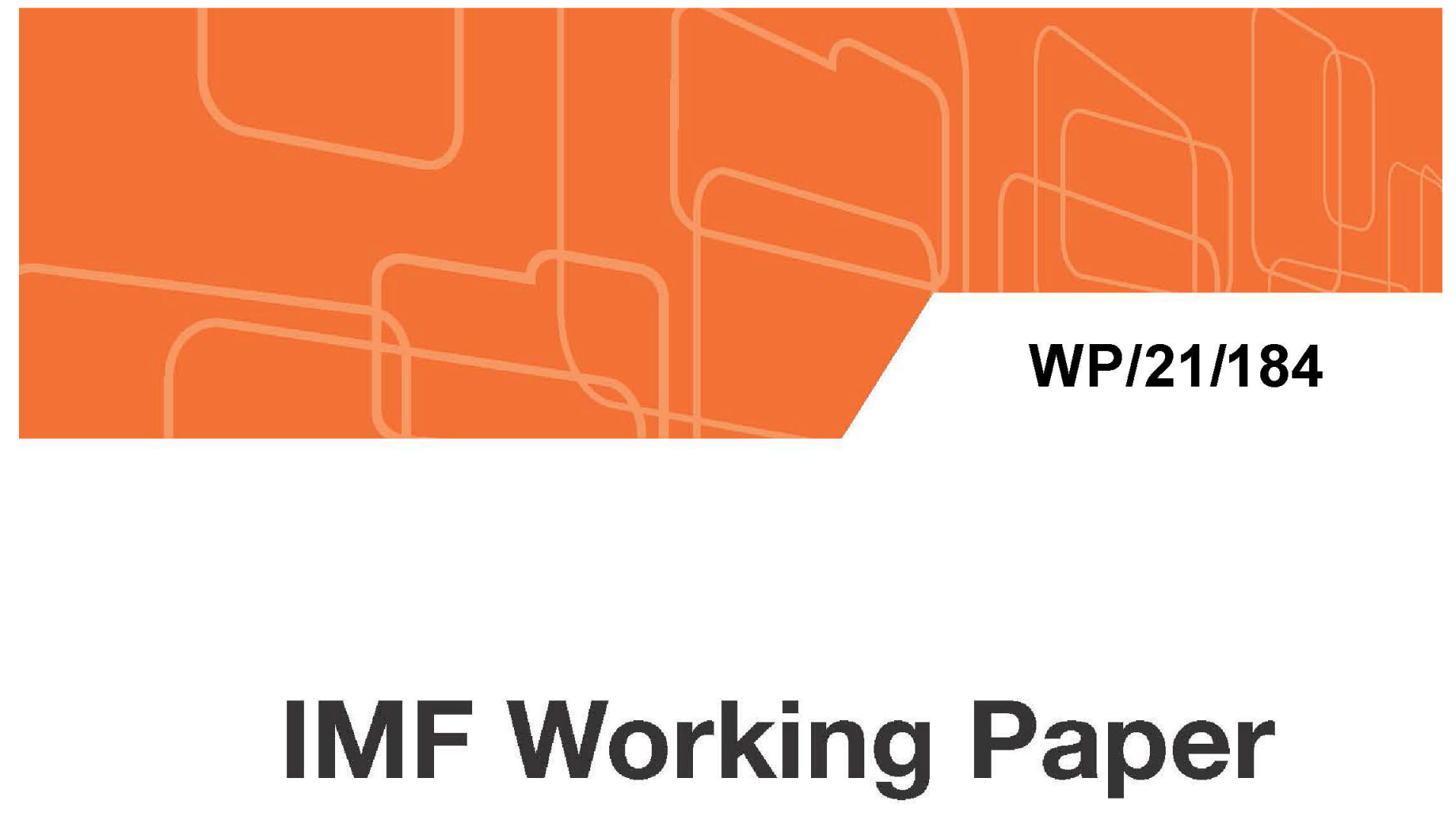

\title{
Market Power and Monetary Policy Transmission
}

by Romain Duval, Davide Furceri, Raphael Lee and Marina M. Tavares

IMF Working Papers describe research in progress by the author(s) and are published to elicit comments and to encourage debate. The views expressed in IMF Working Papers are those of the author(s) and do not necessarily represent the views of the IMF, its Executive Board, or IMF management. 
IMF Working Paper

Research Department

Market Power and Monetary Policy Transmission

Prepared by Romain Duval, Davide Furceri, Raphael Lee and Marina M. Tavares

Authorized for distribution by Romain Duval

July 2021

IMF Working Papers describe research in progress by the author(s) and are published to elicit comments and to encourage debate. The views expressed in IMF Working Papers are those of the author(s) and do not necessarily represent the views of the IMF, its Executive Board, or IMF management.

\begin{abstract}
We show that firms' market power dampens the response of their output to monetary policy shocks, using firm-level data for the United States and a large cross-country firm-level dataset for 14 advanced economies. The estimated impact of a firm's markup on its response to a monetary policy shock is large enough to materially affect monetary policy transmission. We also find some evidence that the role of markup in monetary policy transmission, while independent from other channels, is greater for firms whose characteristics — notably size and age - are likely to be associated with greater financial constraints. We rationalize these findings through a simple partial equilibrium model in which borrowing constraints amplify disproportionately low-markup firms' responses to changes in interest rates.
\end{abstract}

JEL Classification Numbers: E52, E58, D43, L11

Keywords: Monetary policy; interest rates; imperfect competition; market power; markups

Author's E-Mail Address: rduval@imf.org; dfurceri@imf.org; mmendestavares@,imf.org; raphael.sh.lee@,gmail.com 


\section{Contents}

1 Introduction $\underline{2}$

2 Data

2.1 Firm-level data ............................... . . . . . . . . . . . .

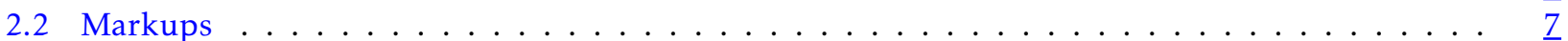

2.3 Monetary policy shocks . . . . . . . . . . . . . . . . . . . . . . . 7

2.3.1 US shocks (for Compustat-based analysis) . . . . . . . . . . . . . .

2.3.2 Monetary policy shocks in 14 advanced economies (for Orbis-based analysis) . . . . . . 10

3 Empirical framework $\underline{11}$

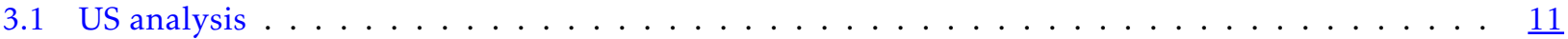

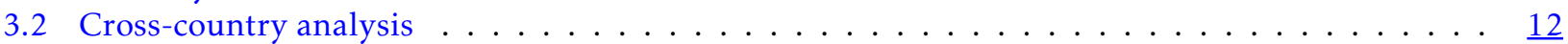

4 Results $\underline{13}$

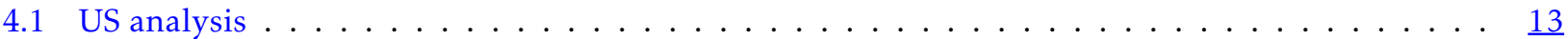

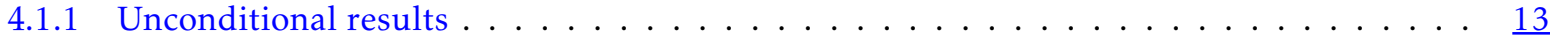

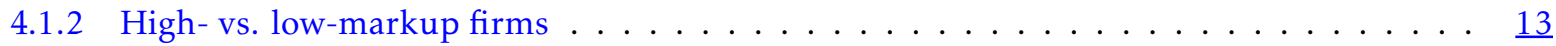

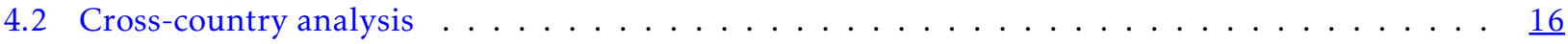

5 Theoretical rationale for the empirical results $\underline{17}$

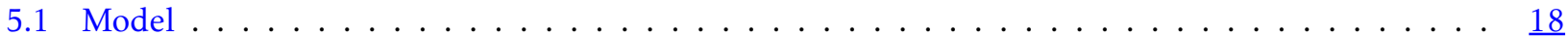

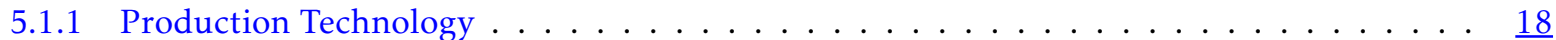

5.1 .2 Cost Structure . . . . . . . . . . . . . . . . . . . . . . . 18

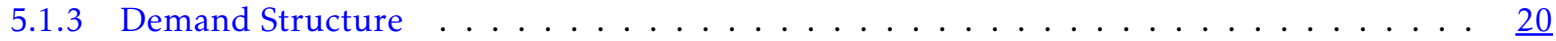

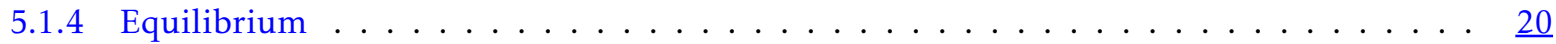

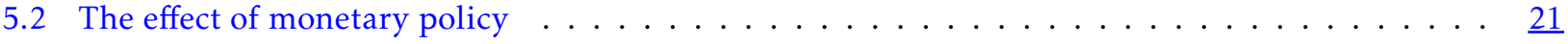

6 Conclusion $\underline{24}$

Bibliography $\underline{26}$

A Appendix

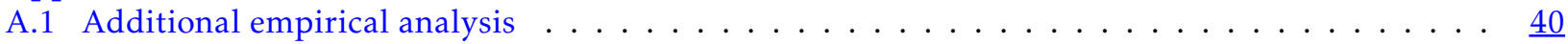

A.2 Robustness Checks (for Compustat-based analysis) . . . . . . . . . . . . . . . . . . . . . . . . . .

A.3 Robustness Checks (for Orbis-based analysis) . . . . . . . . . . . . . . . . . $\underline{48}$

B Theoretical Appendix $\underline{49}$ 


\section{Introduction}

There is growing evidence that price markups, market concentration and corporate profit rates have increased in the United States and, to a lesser extent, in other advanced economies (Autor and Katz (2017); Covarrubias et al. (2019); De Loecker and Eeckhout (2018); De Loecker et al. (2020); Díez et al. (2021)) - although the magnitude of this increase, and whether it can readily be interpreted as evidence of rising corporate market power, remain debated (Basu (2019); Hall (2018); Reenen and John (2018)). In turn, rising market power has the potential to affect the transmission of market policy, in ways that depend on market structure and the source of firms' market power, in particular (Baqaee et al. (2021); Wang and Werning (2020); Syverson (2018)). At the most basic level, to the extent that a higher markup is simply the flip side of a lower elasticity of demand, it will affect, and under certain conditions might mitigate, the response of a firm's output to shocks, such as monetary policy shocks, that affect input costs (Syverson (2018)). Further, in the presence of financial frictions, higher corporate profits associated with higher markups might shelter firms from shocks to external funding conditions, for example by enabling them to keep on financing their working capital or non-pledgeable innovation-enhancing investments (Aghion et al. (2019)); this might also dampen a firm's output response to monetary policy shocks.

While it seems plausible that markups affect monetary policy transmission at the firm level, there is to our best knowledge no direct empirical evidence - although there is an extensive related literature on how different inter-related firm characteristics, such as size and markups, affect the passthrough of cost shocks to prices (among others, Amiti et al. (2019), Berman et al. (2012)). The goal of the present paper is to fill this gap. Using two alternative firm-level datasets respectively for the United States and 14 advanced economies, we examine the role of firms' markup in shaping their real sales' (and investment) response to monetary policy shocks.

Our empirical analysis proceeds in three steps. First, we compute time series for firm-level markups following the method proposed by De Loecker and Warzynski (2012), using (separately) both Compustat data for the United States, and Bureau Van Dijk's Orbis data for a panel of 14 countries. Data cleaning procedures and markup calculations strictly follow De Loecker et al. (2020) for the Compustat dataset, and Díez et al. (2021) for the Orbis dataset. In our context, each dataset has its pros and cons, and using both alternatively enables us to cross-validate our results. Compustat features quarterly data over a long time period (1990-2016 in this paper) but focuses on US public firms, while Orbis only has annual data over a shorter period (2000-2015) but includes private firms, and as such has a better representation of younger firms, for example. Using both datasets also leads us to exploit different exogenous monetary policy shock series For the United States, we use the series put together by Albrizio et al. (2020), who follow Gertler and Karadi (2015) in relying on high-frequency identification of the impact of monetary policy surprises on interest rates. For each of the 14 countries in Orbis, 
we construct the monetary policy shock series as the unexpected change in policy rates that is orthogonal to growth and inflation surprises following, for example, Duval and Furceri (2018) and Furceri et al. (2018).

Next, we estimate the impact of monetary policy shocks on firms' sales growth conditioning on their markup levels, and controlling for unobserved confounding factors (in particular, fixed effects that absorb the average impact of monetary policy shocks on firms' sales growth in each industry — in the US analysis — or country-industry - in the cross-country analysis), as well as observed firm-level confounding factors (firm age, size and financials). Our main variable of interest is firms' real sales, computed as total revenue deflated by (2-digit NACE Rev. 2) industry-level price indices, although we also analyze real fixed assets (deflated using economy-wide capital stock prices) in some extensions of the analysis. We employ the local projection method (Jordà, 2005) to estimate the dynamic response of firms' real sales to monetary policy shocks.

Both across firms within the same industry in Compustat, and across firms within the same country-industry in Orbis, and controlling for our set of unobserved and observed factors driving individual firm sales' growth, we find that high-markup firms' real sales (and fixed assets) respond less to monetary policy shocks than their low-markup counterparts'. This result is robust to a battery of sensitivity checks including sample variations, other markup definitions — such as a Lerner index — and alternative bins for low- and high-markup firms. We also show that our results are unlikely to reflect an impact of monetary policy shocks on the (unobserved) relative price of high-markup firms' sales vis-à-vis low-markup ones' within the same industry, rather than a genuine change in relative real output; in particular, following a monetary policy shock, we do not find any significant change in the relative markup of high-markup firms vis-à-vis low-markup ones. The difference in real sales' response between high- and low-markup firms is not only statistically significant, but also quantitatively large: the difference in the one-year-ahead response of real sales to a 100 basis points monetary policy shock between the top quartile and the bottom quartile of the firm markup distribution is about 2 percentage points in Compustat and 0.8 percentage point in Orbis.

We also find that the role of markups for monetary policy transmission, while independent from other channels, is amplified for firms with characteristics that are typically associated with greater financial frictions, such as (small) size and (young) age. In particular, small low-markup and young low-markup firms are found to be most responsive to monetary policy shocks.

Finally, we offer a rationalization of these findings through a simple partial equilibrium model that sheds light on how differences in markups and tightness of financial constraints across firms shape their relative responses 
to monetary policy shocks. The parsimonious partial equilibrium framework is well-suited for this purpose because our tight differences-in-differences empirical strategy only speaks to the relative, but not the aggregate, impact of markups on firms' response to monetary policy shocks. This model highlights financial frictions as one potential factor behind the role of market power for monetary policy transmission at the firm level.

This paper relates to three strands of literature. The first is the literature on monetary policy transmission at the firm level. Older papers including Gertler and Gilchrist (1994) or Kashyap et al. (1994), among others, highlighted the role of financial frictions for monetary transmission, providing evidence of stronger responsiveness of smaller firms or those that do not have access to bond markets. A more recent literature exploits the growing availability and quality of firm-level data to identify the role of specific financial frictions and estimate their quantitative impact on monetary transmission at the firm level. Cloyne et al. (2018), Anderson and Cesa-Bianchi (2020), and Jeenas (2019) find a sizeable impact of age, leverage, and liquidity, respectively, while Ottonello and Winberry (2020) highlight directly the role of default risk. Here, we show that even after controlling for firm size, age and financial characteristics that have been considered in the recent literature, a firm's markup has a material impact on its responsiveness to monetary policy shocks.

The second, related strand of literature addresses the role of financial frictions for firms' heterogenous response to financial shocks, with particular emphasis on quasi natural experiments related to the 2008-2009 global financial crisis. Studies on the U.S. find that small young firms, firms that were more leveraged or facing greater refinancing risk, or those connected to weaker banks, cut employment more than others (Siemer (2016); Giroud and Mueller (2017); Benmelech et al. (2011); Chodorow-Reich (2014)). Focusing instead on output and productivity, and exploiting German and cross-country firm-level data, respectively, Huber (2017) and Duval et al. (2020) find larger output and productivity losses from the crisis for those firms that were connected to weaker banks and faced greater refinancing risk, respectively. Our paper adds market power to the list of characteristics that can affect a firm's response to financial shocks.

Finally, our paper adds to the fast-growing literature on rising corporate market power and its macroeconomic consequences. A number of recent papers documents an increase in market concentratio (Autor and Katz (2017); Bajgar et al. (2019); Grullon et al. (2019)), profitability (Barkai (2017); Covarrubias et al. (2019)) and price markups (De Loecker and Eeckhout (2018); De Loecker et al. (2020); Díez et al. (2021); Díez et al. (2018)) in the United States and, to a lesser extent, other advanced economies - although the magnitude of these increases and their interpretation remain debated (Basu (2019); Hall (2018); Reenen and John (2018)). These and other papers, including Gutiérrez and Philippon (2016), Fund (2019), Azar et al. (2018) and Benmelech 
et al. (2018), among others, explore empirically the effects of rising market power on a range of economic outcomes including innovation, investment, wages or the labor income share. Yet others trace back major secular macroeconomic trends to increased market power (Caballero, Farhi and Caballero et al. (2017); Eggertsson et al. (2018); Philippon (2019); Stiglitz (2015)). Gutiérrez et al. (2019) analyze the impact on monetary policy transmission using a multi-industry New Keynesian model with monopolistic competition and entry costs. They find that the trend rise in market power has reduced the natural rate of interest and, thereby, made the effective lower bound on policy rates more binding, which amplified the output losses from the 2008-2009 global financial crisis. Baqaee et al. (2021) consider heterogenous firms and Kimball (1995) preferences; they find that, insofar as larger firms have higher markups, their prices should respond less, and their output respond more, to monetary policy shocks than those of smaller, lower-markup firms. Wang and Werning (2020) build a new Keynesian model with oligopolistic competition and find that rising market concentration increases an industry's output responsiveness to monetary policy. Compared with these papers, ours is an empirical study of how a firm's markup shapes its responsiveness to monetary policy shocks, controlling for, and also depending, on other firm characteristics including size or age. Our simple rationalization for our firm-level results emphasizes a combination of heterogeneity in demand elasticities and financial constraints, rather than heterogeneity in price stickiness. A bit closer to our paper, using cross-country firm-level data and focusing on the global financial and 2010-2012 euro area crises, Aghion et al. (2019) and Ahn et al. (2020) find that empirically that high markups help firms stabilize innovation-enhancing investment — such as intangible investment, which cannot be collateralized - and thereby dampen the impact of monetary policy easing. Unlike these papers, ours focuses directly on the impact of market power on monetary policy transmission.

The remainder of the paper is structured as follows. Section 2 describes our firm-level data and the series of monetary policy shocks used in the two (Compustat- and Orbis-based) sets of analyses. Section 3 lays out our empirical framework. Section 4 features our baseline empirical results, extensions and robustness checks. Section 5 presents a simple model and uses it to rationalize our key findings. Section 6 concludes. 


\section{Data}

In this section, we describe the firm-level data, as well as the monetary policy shocks used separately for the United States and the other 14 advanced economies. Since most of the firm-level variables are by now standard in the literature, we focus on the main variables of interest, namely the markup and monetary policy shocks.

\subsection{Firm-level data}

For the Unites States, we draw firm-level variables from quarterly Compustat, a panel of publicly listed U.S. firms. The dataset contains detailed and high-quality balance sheet and income statement data for publicly listed companies for a long panel of firms, from 1986 to 2016. The main advantage of this dataset for our analysis of the effect of monetary policy is that it is quarterly, and therefore well-suited for business cycle analysis. Its main weakness is that it excludes privately held firms which are likely subject to more severe financial constraints and potentially characterized by lower market power. This should be kept in mind when interpreting the results: to the extent that private firms have lower market power than publicly listed firms, our results might downplay the role of markups for aggregate monetary policy transmission. The Compustat dataset is cleaned following the code and procedure of De Loecker et al. (2020). In addition, we drop finance, insurance and real estate (FIRE) industries following Cloyne et al. (2018). After the cleaning, we obtain 424949 observations for 13691 firms over the period 1990-2016.

The firm-level dataset for 14 advanced economies draws from ORBIS, a unique cross-country longitudinal dataset of both listed and non-listed firms provided by Bureau van Dijk. Like Compustat, the dataset features harmonized and rich information on firms' productive activities (for instance, real sales, capital stock, employment), balance sheets and income statements (for instance, debt, assets, tangible and intangible fixed assets, long-term debt). The main advantage of this dataset vis-à-vis Compustat is its more representative firm coverage, most importantly its inclusion of privately held firms. Its main limitation in the context of this paper is that it is available only at annual frequency.

We focus on 14 advanced economies for which we also have information on aggregate monetary policy shocks - namely, the Czech Republic, Germany, Spain, France, the UK, the US, Hungary, Italy, Japan, Korea, the Netherlands, Poland, Slovakia and Turkey. We study firms in the non-farm, non-financial business sector, which corresponds to the two-digit industry codes 5-82 in NACE Rev.2., covering both manufacturing and a number of service sectors, including for example real estate and profession/scientific/technical activities. The "raw" data are cleaned following closely Kalemli-Ozcan et al. (2015), Boz et al. (2017), and Gal (2013). In addition, we exclude very small firms (less than 3 employees), a common practice in studies using firm-level data, due 
to concerns regarding the reliability of the data as well as the consistency of variables over time. Finally, we restrict our analysis to firms that report at least four consecutive periods. After these various steps and once merging the resulting dataset with data on monetary policy shocks at the country-year level, we are left with a dataset containing 14 countries over the period 2001-2015 — for a total of 339,296 firms and more than 2 million observations.

\subsection{Markups}

A firm's markup is defined as the ratio of the price $(\mathrm{P})$ to the marginal cost $(\mathrm{MC})$. Estimating firm markups is empirically challenging for many reasons, one of which being that most firm-level databases (including ORBIS) do not include information on firm-level prices. Here, we follow De Loecker and Warzynski (2012), who derive the following expression for the markup $\left(\mu_{i, t}\right)$ from the firm's cost-minimization problem:

$$
\mu_{i, t}=\frac{P_{i, t}}{M C_{i, t}}=\frac{\partial F_{i, t}(.)}{\partial v_{i, t}} \frac{v_{i, t}}{F_{i, t}(.)} / \frac{P_{i, t}^{v_{i, t}} v_{i, t}}{P_{i, t} Q_{i, t}}=\frac{\beta_{i, t}^{v}}{\alpha_{i, t}^{v}}
$$

where $i$ and $t$ are the subindexes for the firm and year considered, $F_{i, t}($.$) is the firm's production function$ and $V_{i, t}$ refers to any particular flexible input. The firm's markup is thus estimated as the ratio of the output elasticity of the variable input considered $\left(\beta_{i, t}^{v}\right)$ to the expenditure share of that input $\left(\alpha_{i, t}^{v}\right)$. While the latter can be readily computed, the former has to be estimated, which in turn requires estimating a production function. After cleaning both the Compustat and Orbis datasets, markups are estimated at the annual level using the same code as Díez et al. (2021), who in turn apply the De Loecker and Warzynski (2012) methodology. We use the baseline markup in these papers, which relies on a Cobb-Douglas production function estimated using the control function approach of Ackerberg et al. (2015) and considering the cost of goods sold as the variable input.

\subsection{Monetary policy shocks}

Monetary policy can be thought as guided by a rule that takes into account the evolution of the economy. Therefore, in order to be able to infer its causal effects, we need to identify the deviations from this rule (Ramey (2016)). In particular, monetary policy actions need to satisfy three conditions to be deemed exogenous: they must be orthogonal to current and lagged economic conditions; they must be uncorrelated with other exogenous shocks; and, they must be unanticipated. The shocks we use in the analysis seek to satisfy these conditions. 


\subsubsection{US shocks (for Compustat-based analysis)}

We follow the methodology of Albrizio et al. (2020), which identifies exogenous and unexpected Federal Reserve actions using high-frequency data, following Gürkaynak et al. (2005), Gertler and Karadi (2015) — henceforth GK, Nakamura and Steinsson (2018), and Cloyne et al. (2018). In this approach, timing is key for shock identification since monetary policy surprises are captured by changes in the Federal funds futures in a narrow window (e.g., 30 minutes) around the FOMC monetary policy announcements. The identification assumption is that financial market agents react to monetary policy news by exchanging financial positions to the extent they did not expect such policy change, since they had already discounted the information available ex-ante. As these changes are noisy measures of the structural monetary policy shocks, GK use them as instruments for the policy rate in a proxy-SVAR framework. Here, we use them as instruments for the one-year government bond rate in order to be able estimate monetary policy surprises during the post-2008 global financial crisis period over which the zero lower bound was binding (see below). As an illustration of the approach, consider the following reduced-form VAR representation:

$$
Y_{t}=B Y_{t-1}+U_{t}
$$

$Y_{t}$ is a vector of two variables (output, policy rate), $B$ is a 2 by 2 matrix and $U_{t}$ is the vector of the corresponding residuals. Re-writing the equation as follows we obtain the relationship between the residual of the VAR and the structural shocks:

$$
\left(\begin{array}{l}
u_{1, t} \\
u_{2, t}
\end{array}\right)=\left(\begin{array}{ll}
s_{11} & s_{12} \\
s_{21} & s_{22}
\end{array}\right)\left(\begin{array}{l}
e_{1, t} \\
e_{2, t}
\end{array}\right)
$$

To identify the structural shock on the policy rate equation $\left(e_{2, t}\right)-$ the monetary policy shock $-s_{1} 2$ and $s_{2} 2$ need to be identified. The proxy SVAR approach (Stock and Watson (2018), Mertens and Ravn (2014)), relies on external instruments that are contemporaneously correlated with the structural policy shock (relevance condition) and contemporaneously uncorrelated with the other structural shocks (exogeneity condition). This allows to rewrite equation 2 in the following form, and to estimate in a Two-Stage Least Squares (TSLS) framework: (i) the effect of monetary policy surprises on the unexplained part of the government bond rate; and (ii) the ratio $\frac{s_{2} 2}{s_{1} 2}$, recovering the time series of structural shocks $\left(e_{2, t}\right)$. 


$$
u_{1, t}=\frac{s_{22}}{s_{12}} \widehat{u_{2, t}}+w_{t}
$$

where $w$ is as white noise error term.

The additional advantage of this strategy is that it allows to identify monetary policy shocks also during periods when the short-term policy rate is constrained at the zero lower bound. In fact, since unconventional monetary policy contributes to flatten the entire yield curve, changes in futures such as Fed funds futures and Eurodollars can be used to estimate the impact of monetary policy surprises on policy rates at longer horizons and isolate the effect of unexpected changes due to unconventional monetary policy actions.

Following GK approach, we estimate the following VAR over the period 1973m1-2016m8 at monthly frequency:

$$
y_{t}=\left[\log \left(I P_{t}\right), \log \left(C P I_{t}\right), i_{t}, E B P_{t}\right]
$$

where the vector of variables includes: industrial production; the consumer price index; government bond yields and the Gilchrist and Zakrajsek (2012) credit spread. The policy rate included in the VAR is not the Fed fund rates but a government bond rate since the residuals of this equation incorporates exogenous surprises not only in the current Fed funds rate but also in the expected path of interest rates - a key feature of unconventional monetary policy. While GK consider the period 1991q1-2012q6, excluding 2008q7-2009q6 due to the crisis, we extend the analysis up to $2016 \mathrm{q} 3$ to capture monetary policy shocks during the unconventional monetary policy period. In the TSLS estimation, we account for the structural break in $2008 \mathrm{~m} 8$ by allowing the unconventional monetary policy coefficient to differ and, in this way, capture episodes of unexpected balance sheet increases due to large-scale asset purchases. Using the same set of futures rate surprises on FOMC dates as in Gürkaynak et al. (2005) and GK, we test for different combinations of policy rate and instrument ${ }^{1}$. For the baseline analysis, we select the combinations of the one-year government bond rate as the policy rate and the one-month ahead Fed funds future as the instrument. The instrument delivers a positive and statistically significant effect of the change in financial futures on the policy rate (the government bond rate) and is sufficiently strong — the results are very similar and not statistically different when using alternative combinations ${ }^{2}$.

\footnotetext{
${ }^{1}$ The sample consists of one, two and three month ahead monthly Fed funds futures as well as six-month, nine- month and one-year ahead futures on three-month Eurodollar deposits. We kindly thank Karadi for providing us with the updated datasets of Gürkaynak et al. (2005).

${ }^{2}$ Since we have only one instrument and one instrumented variable it is enough to consider the first stage F- statistics and compare
} 


\subsubsection{Monetary policy shocks in 14 advanced economies (for Orbis-based analysis)}

We follow the methodology of Furceri et al. (2018) to construct quarterly measures of exogenous monetary policy shocks for the 14 advanced economies considered in the Orbis-based analysis. Monetary policy shocks are identified in two steps, which closely follow the work of Auerbach and Gorodnichenko (2013) in identifying fiscal shocks in advanced economies. First, the unexpected changes in policy rates (proxied by short-term rates) are computed using the forecast errors of the policy rates provided by Consensus Economics. Second, the forecast errors of the policy rates are regressed on similarly computed forecast errors of inflation and output growth. The monetary policy shocks are then identified as the residuals of this regression. We further purify these surprises from any predictable components by projecting them on current and lagged GDP growth and inflation, in order to eliminate any remaining endogeneity issue. Specifically, we estimate:

$$
F E_{i, t}^{r}=\alpha_{i}+\beta F E_{i, t}^{\Delta y}+\gamma F E_{i, t}^{\pi}+\sum_{j=0}^{4} \delta_{j} \Delta y_{i, t-j}+\sum_{j=0}^{4} \theta_{j} \pi_{i, t-j}+\epsilon_{i, t}
$$

where $F E_{i, t}^{X}(X=r, \Delta y, \pi)$ denotes unexpected changes in the policy rate (proxied by the 3-month rate), real GDP growth, and the inflation rate, respectively - defined as the difference between the actual value at the end of the quarter and the value expected by analysts as of the beginning of the last quarter for each country $i$. $\Delta y_{i, t}$ and $\pi_{i, t}$ are the actual real GDP growth and inflation rates. The estimated residuals $\widehat{\epsilon_{i, t}}$ are then defined as monetary policy shocks for the 14 advanced economies considered in the Orbis-based analysis ${ }^{3}$.

As discussed by Furceri et al. (2018), this methodology has two main advantages. First, it overcomes the issue of "policy foresight" (Leeper et al. (2013)) where economic agents receive news about possible changes in monetary policy and alter their behavior before the actual changes in policy happen. While changes in actual policy rates cannot capture this policy foresight of economic agents, our approach is free from this issue since it uses forecast errors - which already reflect policy foresight by construction. Second, this approach mitigates endogeneity issues as the shocks are orthogonal to unexpected changes in economic activity as well as to current and lagged endogenous variables.

it with Stock and Yogo (2005) critical values. The F corresponding to the combination of the one-year government bond rate and the one-month ahead Fed fund futures is 12 (on average across the regressions of the VAR), and it is above the critical value of significance.

${ }^{3}$ While we use monetary policy shocks identified using forecast data for each individual country, the countries in the euro area are subject to the same policy rate. As such, the shocks for these countries capture their relative exposure to exogenous ECB monetary policy actions. To mitigate this issue, as a robustness check, we repeat our exercise after dropping the euro-area countries other than Germany from the sample. 


\section{Empirical framework}

To estimate the dynamic causal effects of monetary policy shocks on firm's real sales (and investment), we use the local projection method of Jorda (2005). This approach is quite flexible since it allows us to estimate impulse response functions on firm-level panel data controlling for a constellation of fixed effects. Moreover, it is particularly suitable to estimate non-linear effects in the response of the key variables of interest.

Three econometric specifications are used to assess the effect of monetary policy shocks. The first simply aims to confirm that monetary policy shocks have significant effects on firms' real sales and investment. The second specification introduces the role of market power and explores how the effect of monetary policy shocks differs between high- and low-markup firms - after controlling for fixed effects that absorb the aggregate impact of monetary policy shocks, implying that all effects on any particular type of firm should be interpreted as deviations from the average effect (in their industry — in the US analysis — or their country-industry — in the cross-country analysis). The third specification examines whether the differential response of real sales (and investment) between high- and low-markup firms varies with other firm characteristics, including those related to financial frictions.

\subsection{US analysis}

The basic unconditional specification is as follows:

$$
\widetilde{y}_{i, t+h}=\ln \left(y_{i, t+h}\right)-\ln \left(y_{i, t-1}\right)=\alpha_{i}^{h}+\beta^{h} \epsilon_{t}^{m}+\rho^{h} X_{i, t}+\varepsilon_{i, t+h}
$$

where $\tilde{y}_{i, t+h}$ is the difference in the (log) of real sales; $\epsilon_{t}^{m}$ denotes US monetary policy shocks; $\alpha_{i}^{h}$ are firm fixed effects, included to absorb the effect of time-invariant firms' characteristics; $X$ is a vector of controls including two lags of the dependent variable and monetary policy shocks, as well as time-varying firm characteristics (such as size, age, leverage, asset liquidity and tangibility, Tobin's q); $\beta^{h}$ denotes the response to the monetary policy shock at each horizon (quarter) $h$.

The second specification allows the response to vary across firms depending on their markup level. We follow the approach taken by Cloyne et al. (2018) to estimate non-parametrically the heterogeneous effects of monetary policy across different firm characteristics, and estimate the following specification: 


$$
\widetilde{y}_{i, t+h}=\ln \left(y_{i, t+h}\right)-\ln \left(y_{i, t-1}\right)=\alpha_{i}^{h}+\alpha_{s, t+h}^{h}+\sum_{g \in \mathcal{G}} \beta_{g}^{h} \mathbb{1}_{i \in g} \epsilon_{c, t}^{m}+\rho^{h} X_{i, t}+\varepsilon_{i, t+h}
$$

where $\alpha_{s, t+h}$ are sector-time fixed effects that capture differences in how broad sectors respond to monetary policy shocks, and $\mathbb{1}_{i \in g}$ is an indicator variable, which takes value 1 for firms with a markup belonging to bin $g \in G$. Specifically, firms are put into three bins: bottom 25 percentile, top 25 percentile and middle (between the 25 and 75 percentiles) of the distribution of markup levels. To mitigate endogeneity concerns stemming from the fact that firm markups might respond to monetary policy shocks, we use for each firm its (time-invariant) average markup over the entire sample period. That said, following a monetary policy shock, we do not find any significant change in the relative markup of high-markup firms vis-à-vis low-markup ones at the two-to-three-year horizon considered in the analysis (Appendix A) ${ }^{4}$.

As discussed earlier, we are also interested in examining whether the differential response between highand low-markup firms varies with other firm characteristics, including those that relate to financial frictions. To this end, we estimate the following equation:

$$
\widetilde{y}_{i, t+h}=\alpha_{i}^{h}+\alpha_{s, t+h}^{h}+\sum_{g \in \mathcal{G}} \sum_{f \in \mathcal{F}} \beta_{g, f}^{h} \mathbb{1}_{i \in g} \mathbb{1}_{i \in f} \epsilon_{c, t}^{m}+\rho^{h} X_{i, t}+\varepsilon_{i, t+h}
$$

where $\mathbb{1}_{i \in f}$ is an indicator variable that takes value 1 for firms with a given characteristic (age, size, leverage, asset liquidity, asset tangibility, or Tobin's q) belonging to bin $f \in \mathcal{F}$, and $Z$ is a vector of controls. In this specification, the set of controls $Z$ extend the set of controls in $X$ to include the interaction between these additional firms characteristics and US monetary policy shocks $\left(\sum_{f \in \mathcal{F}} \beta_{f}^{h} \mathbb{1}_{i \in f} \epsilon_{c, t}^{m}\right)$. Equations 6-8 are estimated over the period 1990-2016 using OLS, with standard errors clustered by time.

\subsection{Cross-country analysis}

The empirical frameworks for the international panel analysis follow closely those for the US:

\footnotetext{
${ }^{4}$ In the first few quarters after a contractionary monetary policy shock, high-markup firms are even found to lower their relative markup vis-à-vis low-markup firms. This implies that the results in our paper may, if anything, be conservative at such horizon; estimates of equation 8 may under-estimate the decline in the real output of low-markup firms vis-à-vis high-markup ones by failing to account for a possible relative price decline of high-markup firms' goods and services vis-à-vis those of low-markup firms in the same narrowly-defined industry.
} 


$$
\begin{aligned}
& \widetilde{y}_{i, c, t+h}=\ln \left(y_{i, c, t+h}\right)-\ln \left(y_{i, c, t-1}\right)=\alpha_{i}^{h}+\alpha_{c, s, t+h}^{h}+\beta^{h} \epsilon_{c, t}^{m}+\rho^{h} X_{i, c, t}+\varepsilon_{i, c, t+h} \\
& \widetilde{y}_{i, c, t+h}=\alpha_{i}^{h}+\alpha_{c, s, t+h}^{h}+\sum_{g \in \mathcal{G} c} \beta_{g c}^{h} \mathbb{1}_{i \in g c} \epsilon_{c, t}^{m}+\rho^{h} X_{i, c, t}+\varepsilon_{i, c, t+h} \\
& \widetilde{y}_{i, c, t+h}=\alpha_{i}^{h}+\alpha_{c, s, t+h}^{h}+\sum_{g \in \mathcal{G} c} \sum_{f \in \mathcal{F} c} \beta_{g c, f c}^{h} \mathbb{1}_{i \in g c} \mathbb{1}_{i \in f c} \epsilon_{c, t}^{m}+\rho^{h} X_{i, c, t}+\varepsilon_{i, c, t+h}
\end{aligned}
$$

where the subscript $\mathrm{c}$ denotes a country; $\alpha_{c, s, t+h}$ are country-sector-time fixed effects; and the indicator variables for bins of markups $\mathbb{1}_{i \in g c}$ and other firm characteristics $\mathbb{1}_{i \in f c}$ are now country-specific. Equations 6'-8' are estimated over the period 2001-15 using OLS, with standard errors are clustered at the country-sector and time levels.

\section{Results}

\subsection{US analysis}

\subsubsection{Unconditional results}

Estimating the unconditional response of firms' real sales and real assets based on Equation 6 has two purposes. The first is to provide indirect reassurance regarding the validity of our monetary policy shocks, and to compare the response of firms' real sales to that of aggregate output obtained in the literature using national account data. The second objective is simply to quantify the average impact of monetary policy on (low- and highmarkup) firms' real sales. This is because in the subsequent analysis of the role of markups for monetary policy transmission (based on equations 7 and 8), we are only able to compute the effect of monetary policy shocks on low- and high-markup firms relative to the average effect, since the average effect itself is absorbed by time fixed effects. Figure 4 presents the impulse response of real sales (Panel A) and real total assets (Panel B) to a 100-basis point contractionary monetary policy shock. The responses are similar in shape and magnitude, with real sales declining by about $1 \frac{1 / 2}{2}$ percent 12 quarters after the shock. The magnitude and dynamics of the response are broadly similar to those obtained by Albrizio et al. (2020) for GDP using aggregate national account data ${ }^{5}$.

\subsubsection{High- vs. low-markup firms}

In this section, we explore how a firm's markup level shapes its response to monetary policy. We first present how the effect of a monetary policy shock varies between low- and high-markup firms, without controlling for

\footnotetext{
${ }^{5}$ Figure A.1 in Appendix A presents similar results for the restricted sample used in the rest of the paper, which is the (smaller) sample obtained when including all control variables simultaneously.
} 
other firm characteristics (size, age, leverage, asset liquidity and tangibility, and Tobin's q) that may also affect monetary policy transmission. We then present the (marginal) responses of low-versus high-markup firms when controlling for these other firm characteristics. Finally, we explore whether the role of the markup as a transmission channel varies with characteristics that relate to firms' financial constraints.

We begin by looking at how the response of real sales and total assets differs between low- and high-markup firms. Figure 5 reports these responses for firms at the bottom 25th (low-markup) and top 25th (high-markup) percentiles of the markup distribution (left panel), as well as the difference between these two responses (right panel). Again, these results should be read as relative to the average effect, which is absorbed by the sector-time fixed effects. The results indicate that the response of real sales (and total assets) to a contractionary monetary policy shock varies markedly between high- and low-markup firms. Importantly, the difference in responses is not only statistically significant (see right panel of Figure 5), but also quantitatively large: the difference in the one-year-ahead response of real sales to a 100 basis points monetary policy shock between the top quartile and the bottom quartile of the firm markup distribution is about 2 percentage points.

As mentioned in the introduction, a large body of the literature has found that several firms characteristics, especially those related to financial frictions — such as size, age, leverage, asset liquidity and tangibility and Tobin's q - can shape the response of firms' sales and investment to monetary policy. To check whether market power plays a distinct and independent role in the transmission of monetary policy, we extend equation 7 by controlling for the interaction between these other firm characteristics and monetary policy shocks $\sum_{f \in \mathcal{F}} \beta_{f}^{h} \mathbb{1}_{i \in f} \epsilon_{t}^{m}$. As with markups, for each of these alternative characteristics, we assign firms to bins based upon their position in the distribution. Figure 6 presents the results for real sales obtained when including as a control the interaction of monetary shocks with, in turn, size, age, leverage, asset liquidity, asset tangibility and Tobin's q. The results confirm that the response of firms' sales to monetary policy shocks varies markedly between high- and low-markup firms, implying that role of market power in the transmission of monetary policy seems to be independent from other channels. Moreover, the results in Figure A.2 of Appendix A confirm previous findings in the literature that firm size, age and leverage - most clearly here, size — can affect monetary policy transmission at the firm level.

To further confirm that the impact of market power on monetary policy transmission is independent from other channels, and to investigate whether it varies depending on other firm characteristics, we interact monetary policy shocks with the bins of market powers and the bins of other characteristics - in other words, we consider

a triple non-parametric interaction $\sum_{g \in \mathcal{G}} \sum_{f \in \mathcal{F}} \beta_{f}^{h} \mathbb{1}_{i \in g} \mathbb{1}_{i \in f} \epsilon_{t}^{m}$. For example, by looking at the differences in 
responses between low-markup small, low-markup large, high-markup small and high-markup large firms, we can infer the marginal contribution of the markup for a given size and, reciprocally, the contribution of size for a given markup level. Starting with size, Figure 7 shows the responses of real sales to monetary policy shocks for four groups of firms: (i) small low-markup; (ii) large low-markup; (iii) small high-markup; (iv) large high-markup. As can be seen in the top left panel of that figure, smaller firms are generally more responsive to monetary policy shocks than larger ones. This is confirmed in the bottom left panel, which presents the differential response between smaller and larger firms, conditioning on a given level of markup (low or high). This finding is in line with literature, including Gertler and Gilchrist (1994) or Kashyap et al. (1994), among others, that has highlighted the role of financial frictions for monetary transmission, and provided evidence of greater responsiveness of smaller firms or firms that do not have access to bond markets.

Most importantly in our context, the response of small low-markup firms to a monetary policy shock appears to be significantly larger than that of other types of firms; this finding, which will be rationalized theoretically in Section V, suggests that the markup level matters more for the response of credit-constrained firms. The top right panel of Figure 7 shows that the difference in responses between large high-markup firms and small low-markup firms is significantly different from zero; at about 2 percentage points, this difference in responses is also larger in magnitude than the difference in responses between high- and low-markup firms shown in the baseline specification (Equation 7 and Figure 5 above).

Finally, the bottom right panel of Figure 7 presents the differential response between low- and high-markup firms, conditioning on a given size. The difference in response between low- and high-markup firms is statistically significantly different from zero for any level of size. This confirms the important role of markups for monetary policy transmission even when conditioning on a key firm characteristic such as size.

Figure 8 presents qualitatively similar results for age, and so do Figures A.3-A.6 for other firm characteristics. In particular, all these figures confirm the important role of the markup for the transmission of monetary policy even when conditioning on additional firm characteristics.

Summarizing, the evidence for the US suggests that firms' markup is an important transmission channel of monetary policy, independent from, but possibly amplified by, certain firm characteristics related to financial frictions. These results are robust to (i) other markup definitions, based on a Lerner index; and (ii) and alternative bins for low- and high-markup firms (see Appendix A.2). 


\subsection{Cross-country analysis}

This section explores whether the key results obtained on quarterly Compustat data for the United States also hold on annual Orbis data for a panel of advanced economies. Assessing this provides a cross-check for our results, but it is also important in its own right because, as highlighted in De Loecker and Eeckhout (2018), Díez et al. (2021) and Fund (2019), market power has increased in recent decades not only in the United States but also across advanced economies more broadly.

As with the analysis on US data, we conduct three empirical exercises. First, we examine the effect monetary policy shocks on firms' real sales by estimating equation 6'. Next, we estimate equation 7 ' to assess whether this effect differs between high- and low-markup firms. Finally, we run equation 8 ' to examine whether the differential response between high- and low-markup firms varies with other firm's characteristics, including those that relate to financial frictions. Figure 9 presents the results of the first two exercises. The left panel shows the response of real sales to a 100-basis point contractionary monetary policy shock. The peak response for other advanced economies is very similar in magnitude to that obtained for US firms, with real sales declining by about $1 \frac{1}{2}$ percent 2 years after the shock.

The second (middle) panel shows the responses of real sales for firms at the bottom 25th percentile (lowmarkup) and top 25th percentile (high-markup), while the third (right) panel displays the difference in these responses. Here again, the results should be read as relative to the average effect, which is absorbed by the country-sector-time fixed effects. These results show that the response of real sales (relative to the average response absorbed by the fixed effects) is negative and statistically significant for low-markup firms, but it is not statistically significant for high-markup firms. In addition, and in line with the results obtained for the United States, the difference in the responses is not only statistically significant but also quantitatively large, peaking at about 0.8 percentage point one year after a 100 basis points contractionary monetary policy shock. This result is quite robust and holds when controlling for interactions between monetary policy shocks and firm characteristics that relate to financial frictions, such as size, age and leverage (Figure 10) ${ }^{6}$.

Figure 11 presents and compares the responses of real sales to monetary policy shocks for the following four groups of firms: small low-markup; large low-markup; small high-markup; large high-markup. Importantly, small low-markup firms are most responsive to monetary policy shocks (first panel), in line with the results obtained for the United States and the prediction that the markup level should matter more for the response of financially-constrained firms, all else equal. The difference in the one-year response between

\footnotetext{
${ }^{6}$ Similar results are obtained when controlling for the interaction between monetary policy shocks and measures of leverage, asset liquidity, asset tangibility and Tobin's Q.
} 
low-markup-small and high-markup large firms is larger than (almost double) the difference in response between low- and high-markup firms in the baseline specification (Equation 7' and Figure 9 above).

The second panel of Figure 11 shows that smaller firms are more responsive to monetary policy shocks than larger firms - in line with evidence for the US above and the literature, but that holds more strongly for low-markup firms. Finally, and also in line with the US analysis, the third panel shows a significant difference in the responses of low- and high-markup firms for both small and large firms; this confirms the important role of markups for monetary policy transmission even when conditioning on a key firm characteristic such as size.

Figure 12 shows similar, but even stronger results for another firm characteristic that relates to financial frictions, namely age. As predicted, young low-markup firms are most responsive to monetary policy, and the difference in response between old high-markup firms and young low-markup firms is larger than the baseline difference shown above (first panel). While young firms are more responsive to monetary policy than large ones, in line with Cloyne et al. (2018), this holds true primarily for low-markup firms (second panel). Again, reassuringly for the robustness of our main finding, there is a significant difference in the responses of low- and high-markup firms for both young and old firms (third panel).

The results obtained on our panel of advanced countries are also robust to (i) other markup definitions, based on a Lerner index; (ii) alternative bins for low- and high-markup firms; (iii) removing any particular country from the estimation sample (see Appendix A.3).

Summarizing, the results for our panel of advanced countries confirm the evidence for the US that a firm's markup is an important transmission channel of monetary policy, and also suggests that it matters disproportionately for firms - such as small or young firms - that are more likely to be financially constrained. We now rationalize these findings through a simple partial equilibrium model that sheds light on the role of markups and financial frictions for the differences in monetary policy transmission across firms.

\section{Theoretical rationale for the empirical results}

To rationalize motivate our empirical analysis results, in this section we build a simple two-period partial equilibrium model that illustrates that: (i) low-markup firms are generally more responsive than high-markup firms to monetary-policy-driven shifts in the real interest rate; (ii) this difference in responses is larger when monetary policy action removes a binding financial constraint; (iii) the difference in responses between lowand high-markup firms is larger when the firms are initially constrained; (iv) all else equal, if a smaller/younger 
firm faces a binding financial constraint while a larger/older firm is unconstrained (and thereby operates at optimal scale), monetary policy easing will benefit the former (through a lower cost of capital and an easier financial constraint) more than the latter (only through the lower cost of capital).

The model's environment is one in which a profit-maximizing firm produces output using capital and labor as an input. The firm faces an imperfectly elastic demand curve that enables it to charge a price equal to the markup over marginal cost. In addition, the firm faces a borrowing constraint that depends on its initial stock capital and the (real) interest rate. A monetary authority assumed to control the real interest rate then affects the cost of capital, the firm's borrowing constraint, and the whole marginal cost curve. We then proceed to study how, in this simple environment, different firms facing different demand elasticities—and therefore charging different markups—and different borrowing constraints in the first period respond to a monetary policy shock in the second period. Beyond parsimony, the choice of a partial equilibrium model is motivated by the fact that, for identification purposes, our differences-in-differences empirical strategy only speaks to the relative, but not the aggregate, impact of markups on firms' response to monetary policy shocks.

\subsection{Model}

\subsubsection{Production Technology}

The firm combines capital and labor to produce output through the following Cobb-Douglas production function: $Y=k^{\alpha} l^{1-\alpha}, 0<\alpha<1$, where $k$ is capital and $l$ is labor.

\subsubsection{Cost Structure}

The firm initially has $k_{0}$ units of capital and can borrow to increase its capital stock. We find it useful to simplify the model by thinking in terms of the user cost of capital instead of explicitly modeling capital accumulation. To that end, we assume that the firm can increase its stock of capital at the user cost of capital given by $r+\delta$ up to a point that determined by

$$
k \leq \phi(R)+k_{0}
$$

where $k_{0}$ is the firm's initial capital stock, $\mathrm{r}$ the interest rate, $\delta$ depreciation of capital, $R=r+\delta$, and $\phi(R)$ the borrowing constraint. The borrowing constraint $\phi(R)$ could be tied to the initial capital stock $k_{0}$, to a multiple of cash flows, or to the value of the firm; since this does not matter for our results, we keep it general and simply assume it is given by some decreasing function of $R, \phi(R)$. What matters is that monetary policy shifts this constraint by changing the interest rate $r$ and thereby the user cost of capital $\mathrm{R}$. In what follows, we refer to (9) 
as the borrowing constraint.

We assume that investment in capital is reversible (or capital can be sold at some fixed price normalized to one). While the firm may incur some unmodelled fixed cost, its variable cost is given by:

$$
\begin{array}{r}
V C(Q)=\min _{k, l} R k+w l \\
Q=k^{\alpha} l^{1-\alpha} \\
k \leq \phi(R)+k_{0} \\
k, l \geq 0
\end{array}
$$

The firm can increase output by both hiring labor and borrowing funds to increase its capital stock beyond its initial level $k_{0}$ until it hits constraint (9). Upon hitting constraint (9), the firm can still produce more, but only by hiring labor. As a result, the marginal cost curve has two parts. The first part (below a cutoff production level $Q^{*}$ ) is where (9) does not bind and the firm adjusts both capital and labor optimally. The second part (above $Q^{*}$ ) is where (9) binds and the firm only adjusts labor to produce more output. The marginal cost curve steepens, and also becomes concave for $\alpha \in(0,0.5)$; we establish these properties in the lemma below.

Lemma 1 Given interest rate $R$ and wages $w$, the marginal cost curve MC implied by (10) is

$$
M C(Q)=\left\{\begin{array}{l}
\left(\frac{R}{\alpha}\right)^{\alpha}\left(\frac{w}{1-\alpha}\right)^{1-\alpha}, Q \leq Q * \\
\frac{1}{1-\alpha} w Q^{\frac{\alpha}{1-\alpha}}\left(\phi(R)+k_{0}\right)^{\frac{-\alpha}{1-\alpha}}
\end{array}\right.
$$

where $Q^{*}$ is given by

$$
Q^{*}(R)=\left(\frac{R}{w} \frac{1-\alpha}{\alpha}\right)^{1-\alpha}\left(\phi(R)+k_{0}\right)
$$

All proofs for the lemmas in this section are in Appendix B. A monetary policy shock that lowers the real interest rate $r$ has two effects on the marginal cost. First, by reducing the user cost of capital $R$, it lowers the marginal cost regardless of whether the firm is constrained or unconstrained. Second, it changes the cutoff level of output $Q^{*}$ at which the constraint kicks in. The total effect on the cutoff $Q^{*}$ depends on whether the credit constraint effect is greater than the interest rate effect. When this is the case, $Q^{*}$ is decreasing in $\mathrm{R}$ and hence that monetary policy relaxes the firm's constraint in (11). Lemma 1 formalizes this condition: 
Lemma 2 Given the interest rate $r$-and therefore user cost of capital $R$ :

$$
\frac{\partial Q^{*}}{\partial R} \leq 0 \text { if and only if }-\frac{\phi^{\prime}(R)}{\left(\phi(R)+k_{0}\right)} \geq \frac{(1-\alpha)}{R}
$$

Assumption 1 We assume that $\phi(\cdot)$ is such that $-\frac{\phi^{\prime}(R)}{\left(\phi(R)+k_{0}\right)} \geq \frac{(1-\alpha)}{R}$ and hence $Q^{*}$ in (11) is strictly decreasing in $R$.

\subsubsection{Demand Structure}

Firm profits are given by:

$$
\Pi=\max _{q} p q-V C(q)-F C
$$

subject to

$$
q=\kappa^{\xi} p^{-\xi}
$$

where $V C(\cdot)$ is the solution of problem (10) and $F C$ is some unspecified fixed cost that is sufficiently low to ensure that profits are positive and the firm continues to operate. This has the standard implication that the firm charges each customer a constant markup over marginal cost, and that output sold depends on both the marginal cost and the elasticity of substitution $\xi$.

Lemma 3 A profit-maximizing firm equalizes marginal revenue $(M R)$ and marginal cost $(M C)$ :

$$
M R(q)=\kappa \frac{\xi-1}{\xi} q^{-1 / \xi}=M C(q)
$$

whose solution is $p=\frac{\xi}{\xi-1} M C(q)$. The marginal revenue curve is decreasing in $\xi$, implying that-for given output—a high-markup firm has a steeper marginal revenue schedule and responds less to shifts in the marginal cost curve.

\subsubsection{Equilibrium}

Given interest rate $\mathrm{r}$ and wage $w$, equilibrium is quantity $q^{*}$ and price $p^{*}$ that solve the firm's profit maximization problem (10). Figure 1a illustrates the equilibrium when the firm is financially unconstrained (i.e., equation (9) is not binding), while figure $1 \mathrm{~b}$ illustrates the equilibrium when the firm is financially constrained. 
Figure 1: Equilibrium

(a) A. Unconstrained Firms

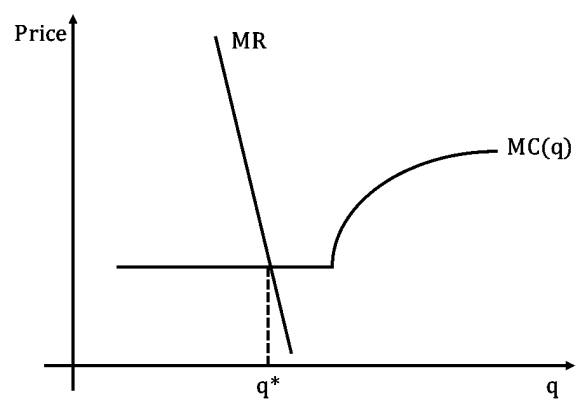

(b) B. Constrained Firms

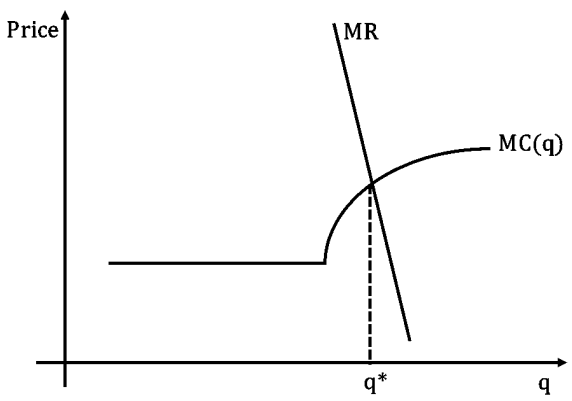

\subsection{The effect of monetary policy}

We now turn to the analysis of how the effect of monetary policy on output (sales) depends on the elasticity $\xi$ faced-and therefore the markup charged—by the firm and whether it is credit-constrained. Our comparative statics considers four types of firms corresponding to the four possible combinations of markups (high or low) and credit constraints (binding or non-binding). To keep the focus strictly on these two features, we consider two high- and low-markup firms that produce the same output $q *$ and have the same cost structure before $\mathrm{r}$ changes.

Assumption 2 . All firm types have the same cost structure and face the same borrowing constraints—i.e., they have the same $k_{0}$ and $\phi(R)$. As a matter of normalization, the preference shifter $\kappa(\xi)$ is such that (initial) output $q *$ is identical across all firm types.

We begin by characterizing the effect of monetary policy shock on the marginal cost curve, before turning to the effect of monetary policy on output for different firm types.

Lemma 4 For a given output $q$, a decline in $r$ leads to a larger fall in marginal cost on the constrained portion of the MC curve than it does on the unconstrained portion.

The impact of a monetary policy shock on the marginal cost curve follows from Lemma 1 and Lemma 2, and it is summarized in Figure 2. An interest rate cut has two effects on the marginal cost curve: (i) an interest rate effect, which shifts the curve downwards; and (ii) a borrowing constraint effect, which flattens it (for $q>q^{L}$ ). Lemma 4 follows from the observation that the constrained portion of the marginal cost curve is affected by both the interest rate and borrowing constraint effects, while the unconstrained portion is only affected by the interest rate effect. In addition, per Assumption 1, a fall in $r$ also raises the cutoff output value above which the constraint becomes binding (from $q^{L}$ to $q^{H}$ ). 
Figure 2: The Impact of an Interest Rate Cut on the Marginal Cost Curve

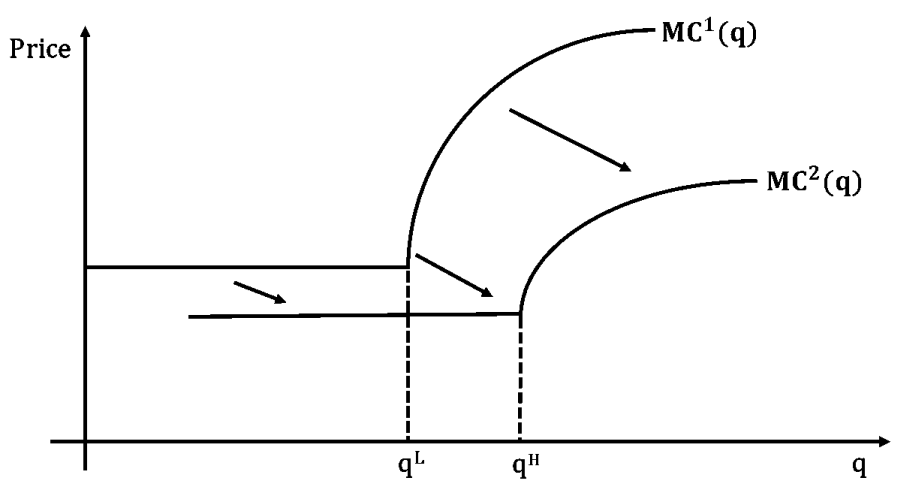

Figure 3: The Impact of an Interest Rate Cut on High- and Low-Markup Firms

(a) A. Unconstrained Firms (Case 1)

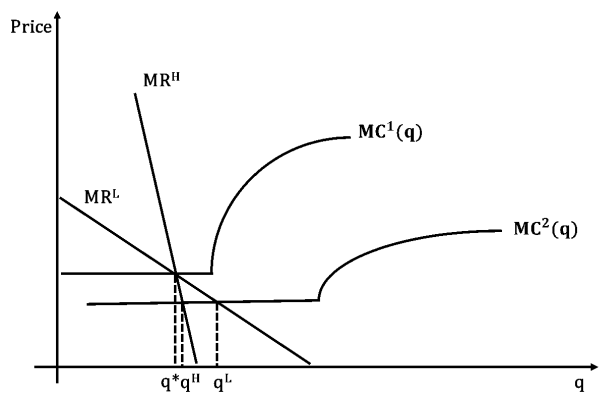

(b) B. Constrained Firms (Case 2)

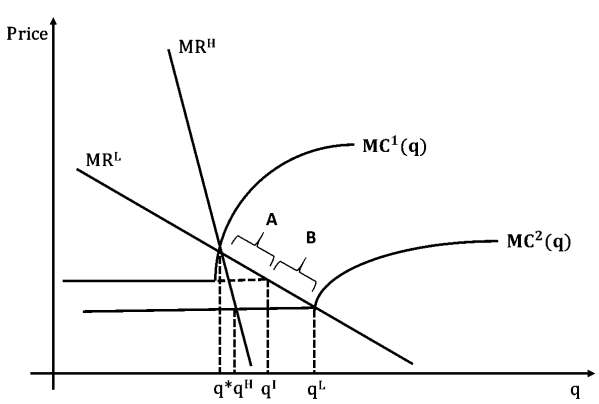

We are now ready to analyze the impact of an interest rate shock under alternative initial markup levels and financial constraints.

\section{Case 1. Financially unconstrained firms}

If the high- and low-markup firms are both financially unconstrained ex ante and ex post, the low-markup firm's output responds more to the interest rate shock. This is the "textbook" case illustrated in Figure 3a. The marginal revenue curves of firm $H$ (high markup) and $L$ (low markup) initially cross the unconstrained part of their (common) marginal cost curve at the same point $q^{*}$. Following the decline in $r$, the $M C$ curve shifts from $M C^{1}$ to $M C^{2}$, and the low-markup firm $L$ increases its output level more (from $q^{*}$ to $q^{L}$ ) than the high-markup firm $H$ (from $q^{*}$ to $q^{H}$ ) because the former has a flatter MR curve. This is formalized in Lemma 5.

Lemma 5 . If high-and low-markup firms are both financially unconstrained ex ante and ex post, and they initially have the same output level $q^{*}$, then a reduction in the interest rate triggers a larger response of the low-markup firm $\left(q^{L}>q^{H}\right)$ for a sufficient large $\kappa .^{7}$

\footnotetext{
${ }^{7}$ Formally, it is sufficient that $\kappa>\left(\frac{r}{\alpha}\right)^{\alpha}\left(\frac{w}{1-\alpha}\right)^{(1-\alpha)} \frac{\xi}{\xi-1}$.
} 
It is also possible that a decline in interest rate $r$ causes firms to become financially constrained. Lemma 6 states that, because of its flatter $M R$ curve, the low-markup firm is the first to become financially constrained. Its output response to the interest rate shock will be smaller than if it were unconstrained, but still greater than that of the high-markup firm. Further, if both firms become financially constrained, it is straightforward to show that the low-markup firm's output response is still greater than that of its high-markup counterpart (see Appendix B).

Lemma 6 . Consider high-and low-markup firms that are both financially unconstrained and have the same output level $q^{*}$ ex ante. If only one firm becomes financially constrained following a decline in the interest rate, it will be the low-markup firm.

\section{Case 2. Financially constrained firms}

If the two firms are financially constrained ex ante and ex post, the low-markup firm will respond more to the interest rate shock because the constrained portion of the marginal cost curve is increasing in the quantity produced $q$ and the $M R$ curve of the low-markup firm is flatter. This result is formalized in the Lemma below.

Lemma 7 If high-and low-markup firms are both financially constrained ex ante and ex post, and they initially have the same output level $q^{*}$, then a reduction in the interest rate triggers a larger output response of the low-markup firm $\left(q^{L}>q^{H}\right)$ for a sufficient large initial capital stock initial capital stock $k_{0}$ and constant $\kappa^{8}$

If both firms are financially constrained ex ante but one firm becomes financially unconstrained ex post, it is straightforward to show that the latter will be the low-markup firm. We illustrate the case where both firms are financially constrained ex ante and become financially unconstrained ex post in Figure $3 \mathrm{~b}$ and formalize it in Lemma 8.

Lemma 8 Consider high-and low-markup firms that are both financially constrained and have the same output level $q^{*}$ ex ante. If only one firm becomes financially unconstrained following a decline in the interest rate, it will be the low-markup firm.

If the two firms are financially constrained ex ante and the interest rate decline lifts the constraint for both, the difference in response between the low- and high-markup firms is larger than in the unconstrained case. This is an important implication of the characterization of the $M C$ curve formalized in Lemma 4, and it is illustrated in Figure 3b. The interest rate shock shifts the $M C$ curve from $M C^{1}$ to $M C^{2}$, resulting in both the low- and high-markup firms becoming unconstrained and achieving their optimal scales $\left(q^{L}\right.$ and $\left.q^{H}\right)$. The interest rate decline is more powerful in this case, because it relaxes the borrowing constraint (raising output by

\footnotetext{
${ }^{8}$ Formally, it is sufficient $\kappa>\frac{w}{1-\alpha} \frac{\xi-1}{\xi}$ and $k_{0}>1-\phi(R)$.
} 
the difference between $q^{*}$ and $q^{I}$ (region A)) in addition to reducing the cost of capital (which raises output by the difference between $q^{I}$ and $q^{H}$ (region B)). Most importantly in our context, it is disproportionately more powerful for the low-markup firm (as can be seen by comparing Panels A and B).

\section{Interplay between financial constraints and markups}

Finally, to illustrate the interplay between financial constraints and markups, let us depart from our initial assumption that both firms face the same cost structure implying the same marginal cost curve. Instead, we assume one firm to be unconstrained and the other to be constrained-possibly because the latter is younger, with greater information asymmetry between the firm and creditors. In this case, all else equal, an interest rate decline benefits the constrained firm more, since it enjoys not only a lower cost of capital but also a looser borrowing constraint. Most importantly in our context, the difference in output responses between the constrained and unconstrained firms is larger the lower the markup of the constrained firm is-that is, the farther it operates from its optimal scale before the interest rate cut. This result, which is in line with our empirical analysis, is a straightforward consequence of Lemma 4.

\section{Summing up}

To sum up, our stylized partial equilibrium model yields two results that line up with our empirical findings: i) low-markup firms are more responsive to interest rate shifts than high-markup ones, all else equal; and ii) that role of markups for the response of output is greater when firms face tighter financial constraints. ${ }^{9}$

\section{Conclusion}

There is growing evidence that price markups, market concentration and corporate profit rates have increased in the United States and, to a lesser extent, in other advanced economies. It is not therefore surprising that many recent contributions have examined empirically the effects of rising market power on a range of economic outcomes including innovation, investment, wages or the labor income share. Yet, while it seems plausible that markups also affect the transmission of monetary policy, there is to our best knowledge no direct empirical evidence of such effect, although there is a related literature on how inter-related firm characteristics, such as

\footnotetext{
${ }^{9}$ The main results from our simple analysis could be rationalized through a more complex model that would capture the life cycle of firms. In this environment, firms grow because they acquire more customers and capital over time. Young firms are small and likely to be credit-constrained. They are small because they need to acquire more customers to grow their own demand, and because they have a low stock of capital. Old large firms have a customer base that is no longer growing, and they are financially unconstrained. Luttmer (2011), Drozd and Nosal (2012), Foster et al. (2015), Gourio and Rudanko (2014) provide some analysis of how customer growth matters for firm growth.
} 
size and markups, shape the pass through of cost shocks to prices.

This paper fills this gap by using two alternative firm-level datasets respectively for the United States and 14 advanced economies, and recent measures of markups and exogenous monetary policy shocks.

The results suggest that high-markup firms' real sales (and real fixed assets) respond significantly less to monetary policy shocks than their low-markup counterparts. This difference in real sales' response between high- and low-markup firms is not only statistically significant, but also quantitatively large: the difference in the one-year-ahead response of real sales to a 100 basis points monetary policy shock between the top quartile and the bottom quartile of the firm markup distribution is about 2 percentage points in Compustat (US) and 0.8 percentage point in Orbis (14 advanced economies).

Moreover, we show that even after controlling for firm size, age and financial characteristics that have been considered in the recent literature, a firm's markup has a material impact on its responsiveness to monetary policy shocks. This result suggests that the role of markup in the transmission of monetary policy is independent from other channels.

Finally, we find suggestive evidence that financial frictions amplify the impact of markups on firms' responsiveness to monetary policy. Our results confirm these previous findings on the role of firms age and size in affecting the transmission of monetary policy, and also show that while the stronger responsiveness of low-markup firms vis-à-vis high-markup firms holds for both small and large firms, as well as for both young and old firms, smaller or younger firms tend to be most responsive to monetary policy. 


\section{Bibliography}

Ackerberg, D., Caves, K., and Frazer, G. (2015). Identification properties of recent production function estimators. Econometrica, 83(6):2411-2451.

Aghion, P., Farhi, E., and Kharroubi, E. (2019). Monetary policy, product market competition and growth. Economica, 86(343):431-470.

Ahn, J., Duval, R., and Sever, C. (2020). Macroeconomic Policy, Product Market Competition, and Growth: The Intangible Investment Channel. IMF Working Papers 2020/025, International Monetary Fund.

Albrizio, S., Flores, J., and Furceri, D. (2020). Non-linear Macro and Distributional Effects of US Monetary Policy. IMF Working Paper 17/184, International Monetary Fund.

Amiti, M., Itskhoki, O., and Konings, J. (2019). International shocks, variable markups and domestic prices. Quarterly Journal of Economics, 86(6):2356-2402.

Anderson, G. and Cesa-Bianchi, A. (2020). Crossing the credit channel; credit spreads and firm heterogeneity. Bank of England Staff Working Paper, 854.

Auerbach, A. and Gorodnichenko, Y. (2013). Measuring the output responses to fiscal policy. American Economic Journal: Economic Policy, 4(2):1-27.

Autor, D. and Katz, L. (2017). Concentrating on the fall of the labor share. American Economic Review, 107(50):180-85.

Azar, J. A., Marinescu, I., Steinbaum, M. I., and Taska, B. (2018). Concentration in US Labor Markets: Evidence From Online Vacancy Data. NBER Working Papers 24395, National Bureau of Economic Research, Inc.

Bajgar, M., Berlingieri, G., Calligaris, S., Criscuolo, C., and Timmis, J. (2019). Industry concentration in europe and north america. OECD Productivity Working papers, 18.

Baqaee, D., Farhi, E., and Sangani, K. (2021). The Supply-Side Effects of Monetary Policy. NBER Working Papers 28345, National Bureau of Economic Research, Inc.

Barkai, S. (2017). Declining labor and capital shares. Unpublished manuscript, University of Chicago.

Basu, S. (2019). Are Price-Cost Markups Rising in the United States? A Discussion of the Evidence. NBER Working Papers 26057, National Bureau of Economic Research, Inc.

Benmelech, E., Bergman, N., and Kim, H. (2018). Strong Employers and Weak Employees: How Does Employer Concentration Affect Wages? NBER Working Papers 24307, National Bureau of Economic Research, Inc. 
Benmelech, E., Bergman, N., and Seru, A. (2011). Financing Labor. NBER Working Papers 17144, National Bureau of Economic Research, Inc.

Berman, N., Martin, P., and Mayer, T. (2012). How do different exporters react to exchange rate changes? Quarterly Journal of Economics, 127(1):437-492.

Boz, E., Gopinath, G., and Plagborg-Møller, M. (2017). Global Trade and the Dollar. NBER Working Papers 23988, National Bureau of Economic Research, Inc.

Caballero, R., Farhi, E., and Gourinchas, P.-O. (2017). Rents, technical change, and risk premia accounting for secular trends in interest rates, returns on capital, earning yields, and factor shares. American Economic Review Papers and Proceedings, 107(5):614-20.

Chodorow-Reich, G. (2014). The employment effects of credit market disruptions: Firm-level evidence from the 2008-9 financial crisis. Quarterly Journal of Economics, 129(1):1-59.

Cloyne, J., Ferreira, C., Froemel, M., and Surico, P. (2018). Monetary Policy, Corporate Finance and Investment. NBER Working Papers 25366, National Bureau of Economic Research, Inc.

Covarrubias, M., Gutiérrez, G., and Philippon, T. (2019). From Good to Bad Concentration? U.S. Industries over the past 30 years. NBER Working Papers 25983, National Bureau of Economic Research, Inc.

De Loecker, J. and Eeckhout, J. (2018). Global market power. NBER Working Paper 24768, National Bureau of Economic Research, Cambridge, MA.

De Loecker, J., Eeckhout, J., and Unger, G. (2020). The rise of market power and the macroeconomic implications. The Quarterly Journal of Economics, 135(2):561-644.

De Loecker, J. and Warzynski, F. (2012). Markups and firm-level export status. American Economic Review, 102(6):2437-71.

Drozd, L. and Nosal, J. (2012). Understanding international prices: Customers as capital. American Economic Review, 102(1):364-395.

Duval, R. and Furceri, D. (2018). The effects of labor and product market reforms: The role of macroeconomic conditions and policies. IMF Economic Review, 66:31-69,.

Duval, R., Hong, G. H., and Timmer, Y. (2020). Financial frictions and the great productivity slowdown. Review of Financial Studies, 133(2):475-503.

Díez, F., Fan, J., and Villegas-Sanchez, C. (2021). Global declining competition. Journal of International Economics. 
Díez, F., Leigh, D., and Tamburletchai, S. (2018). Global market power and its macroeconomic implications. In IMF Working Paper 18/137. International Monetary Fund, Washington, D.C.

Eggertsson, G. B., Robbins, J. A., and Wold, E. G. (2018). Kaldor and Piketty's Facts: The Rise of Monopoly Power in the United States. NBER Working Papers 24287, National Bureau of Economic Research, Inc.

Foster, L., Haltiwanger, J., and Syverson, C. (2015). The slow growth of new plants: Learning about demand? Economica, 83(329):91-129.

Fund, I. M. (2019). The rise of corporate market power and its macroeconomic effects. World Economic Outlook, Chapter, 2.

Furceri, D., Loungani, P., and Zdzienicka, A. (2018). The effects of monetary policy shocks on inequality. Journal of International Money and Finance, 85:168-86.

Gal, P. N. (2013). Measuring Total Factor Productivity at the Firm Level using OECD-ORBIS. OECD Economics Department Working Papers 1049, OECD Publishing.

Gertler, M. and Gilchrist, S. (1994). Monetary policy, business cycles, and the behavior of small manufacturing firms. Quarterly Journal of Economics, 109(2):309-40,.

Gertler, M. and Karadi, P. (2015). Monetary policy surprises, credit costs, and economic activity. American Economic Journal: Macroeconomics, 7(1):44-76.

Gilchrist, S. and Zakrajsek, E. (2012). Credit spreads and business cycle fluctuations. American Economic Review, 102(4):1692-1720.

Giroud, X. and Mueller, H. (2017). Firm leverage, consumer demand, and employment losses during the great recession. The Quarterly Journal of Economics, 132(1):271-316.

Gourio, F. and Rudanko, L. (2014). Customer Capital. Review of Economic Studies, 81(3):1102-1136.

Grullon, G., Larkin, Y., and Michaely, R. (2019). Are US Industries Becoming More Concentrated? Review of Finance, 23(4):697-743.

Gutiérrez, G., Jones, C., and Philippon, T. (2019). Entry Costs and the Macroeconomy. NBER Working Papers 25609, National Bureau of Economic Research, Inc.

Gutiérrez, G. and Philippon, T. (2016). Investment-less Growth: An Empirical Investigation. NBER Working Papers 22897, National Bureau of Economic Research, Inc. 
Gürkaynak, R. S., Sack, B., and Swanson, E. (2005). The sensitivity of long-term interest rates to economic news: Evidence and implications for macroeconomic models. American Economic Review, 95(1):425-436.

Hall, R. E. (2018). Using Empirical Marginal Cost to Measure Market Power in the US Economy. NBER Working Papers 25251, National Bureau of Economic Research, Inc.

Huber, K. (2017). Disentangling the effects of a banking crisis: Evidence from german firms and counties. American Economic Review, 108(3):868-98.

Jeenas, P. (2019). Firm balance sheet liquidity, monetary policy shocks and investment dynamics. Unpublished manuscript.

Jorda, O. (2005). Estimation and inference of impulse responses by local projections. American Economic Review, 95:161-82.

Kalemli-Ozcan, S., SÃşrensen, B., Villegas-Sanchez, C., Volosovych, V., and Yesiltas, S. (2015). How to construct nationally Representative Firm Level Data from the ORBIS Global Database. Tinbergen Institute Discussion Papers 15-110/IV, Tinbergen Institute.

Kashyap, A., Lamont, O., and Stein, J. (1994). Credit conditions and the cyclical behavior of inventories. Quarterly Journal of Economics.

Kimball, M. S. (1995). The quantitative analytics of the basic neomonetarist model. Journal of Money, Credit and Banking, 27(4):1241-1277.

Leeper, E. M., Walker, T. B., and Yang, S.-C. S. (2013). Fiscal foresight and information flows. Econometrica, 81(3):1115-1145.

Luttmer, E. G. J. (2011). On the Mechanics of Firm Growth. The Review of Economic Studies, 78(3):1042-1068.

Mertens, K. and Ravn, M. O. (2014). A reconciliation of SVAR and narrative estimates of tax multipliers. Journal of Monetary Economics, 68(S):1-19.

Nakamura, E. and Steinsson, J. (2018). Identification in macroeconomics. Journal of Economic Perspectives, 32(3):59-86.

Ottonello, P. and Winberry, T. (2020). Financial Heterogeneity and the Investment Channel of Monetary Policy. Econometrica, 88(6):2473-2502.

Philippon, T. (2019). The Great Reversal: How America Gave up on Free Markets. The Belknap Press of Harvard University, Cambridge, MA. 
Ramey, V. (2016). Macroeconomic Shocks and Their Propagation. In Taylor, J. B. and Uhlig, H., editors, Handbook of Macroeconomics, volume 2 of Handbook of Macroeconomics, chapter 0, pages 71-162. Elsevier.

Reenen, V. and John (2018). Increasing differences between firms: Market power and the macro-economy. CEP Discussion Paper 1576, CEP, London, England.

Siemer, M. (2016). Firm entry and employment dynamics in the great recession. Finance and Economics Discussion Series 2014-56, Board of Governors of the Federal Reserve System.

Stiglitz, J. E. (2015). New Theoretical Perspectives on the Distribution of Income and Wealth among Individuals: Part I. The Wealth Residual. NBER Working Papers 21189, National Bureau of Economic Research, Inc.

Stock, J. and Yogo, M. (2005). Testing for Weak Instruments in Linear IV Regression. Cambridge University Press, New York.

Stock, J. H. and Watson, M. W. (2018). Identification and Estimation of Dynamic Causal Effects in Macroeconomics Using External Instruments. Economic Journal, 128(610):917-948.

Syverson, C. (2018). Changing market structure and implications for monetary policy. In Remarks at the 2018 Jackson Hole Symposium. Federal Reserve Bank of Kansas City.

Wang, O. and Werning, I. (2020). Dynamic Oligopoly and Price Stickiness. NBER Working Papers 27536, National Bureau of Economic Research, Inc. 
Figure 4: Response of real sales and total assets to US monetary policy shocks

(a) Panel A. Real sales (\%)

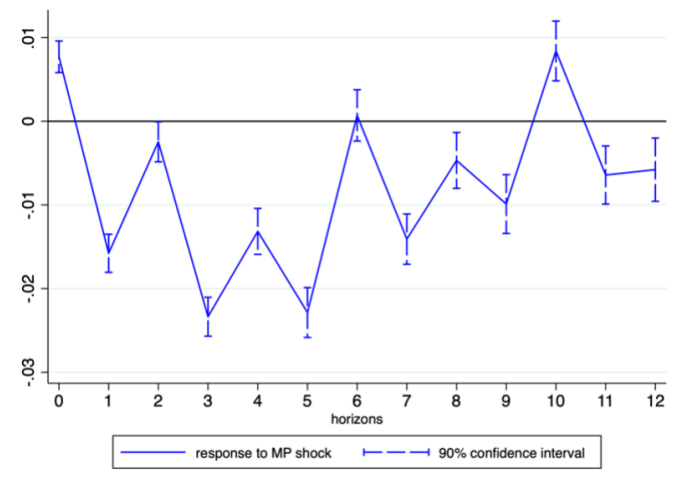

(b) Panel B. Real total assets (\%)

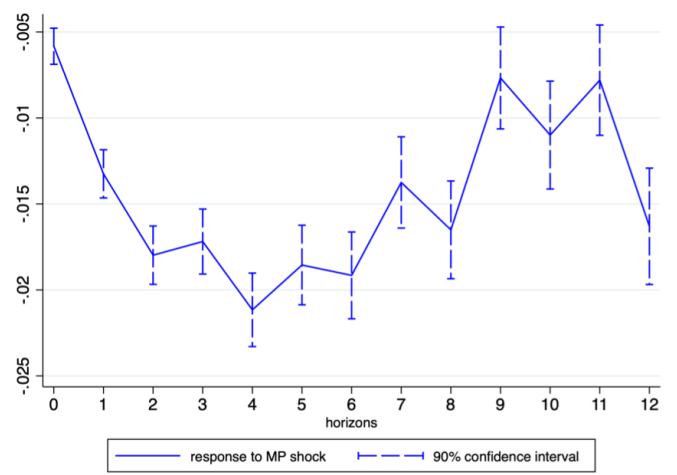

Note: the solid lines indicate the response of real sales (total assets) to a 100-basis point monetary policy shock; the vertical lines denote 90 percent confidence bands. The $\mathrm{x}$-axis denotes time. $\mathrm{t}=0$ is the quarter of the shock. The estimates are based on equation 6

Figure 5: Response of real sales and total assets to US monetary policy shocks: high-vs. low-markup firms

(a) Panel A. Real sales (\%)
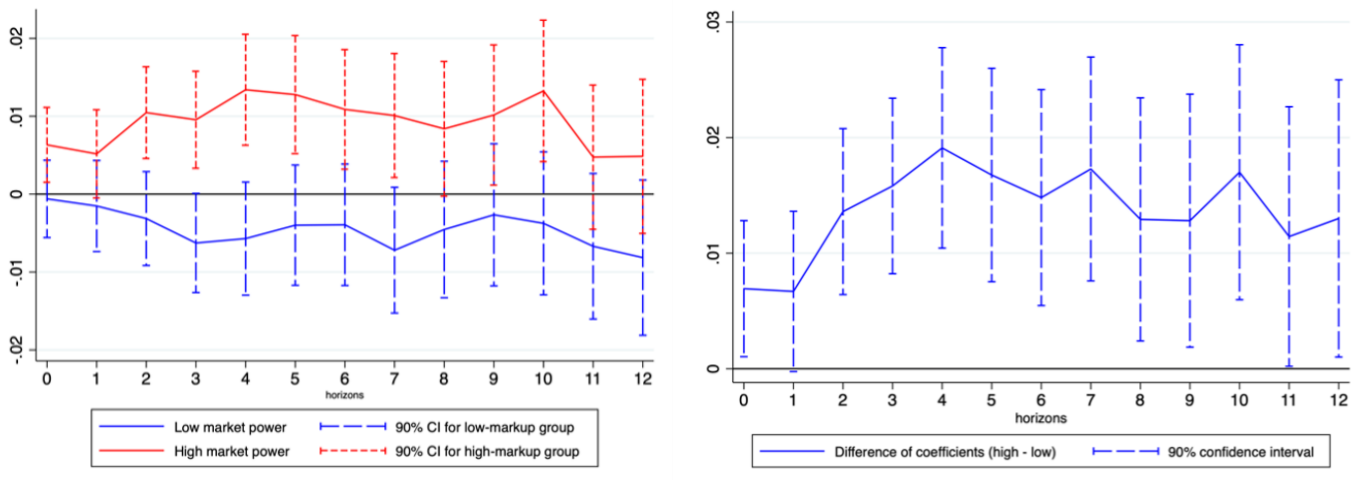

(b) Panel B. Real total assets (\%)
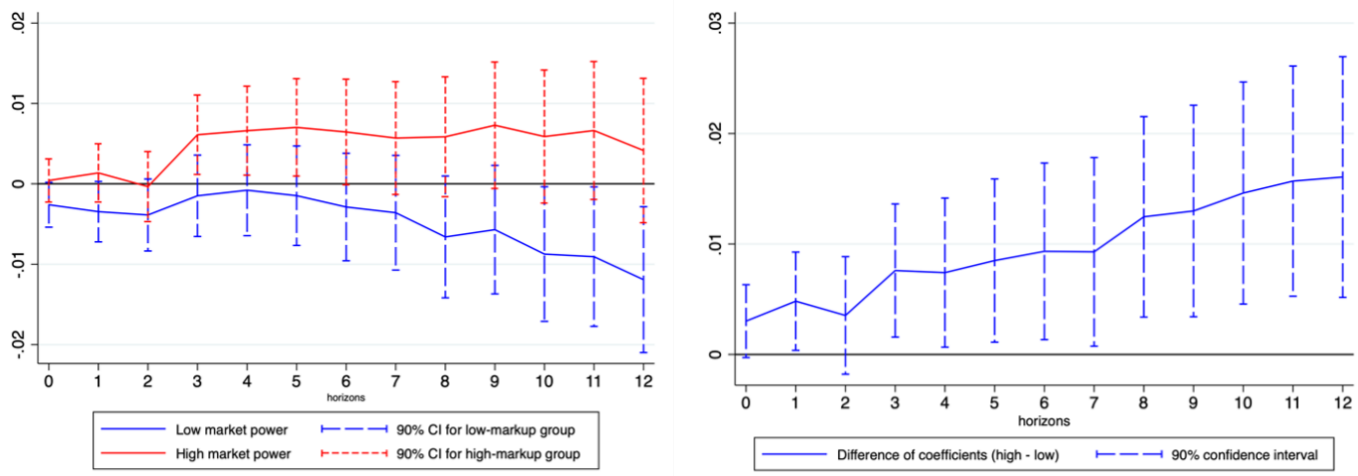

Note: the solid lines indicate the response of real sales (total assets) to a 100-basis point monetary policy shock; the vertical lines denote 90 percent confidence bands. The $\mathrm{x}$-axis denotes time. $\mathrm{t}=0$ is the quarter of the shock. The estimates are based on equation 7 
Figure 6: Response of real sales to US monetary policy shocks: high- vs. low-markup firms — controlling for interaction between monetary policy shocks and:

(a) Panel A. Size (\%)
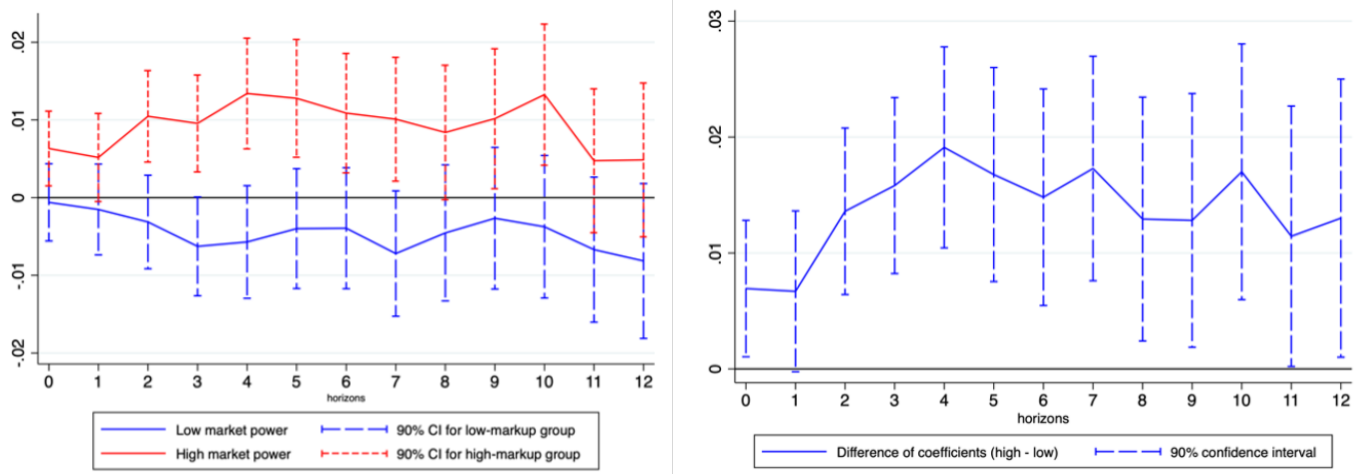

(b) Panel B. Age (\%)
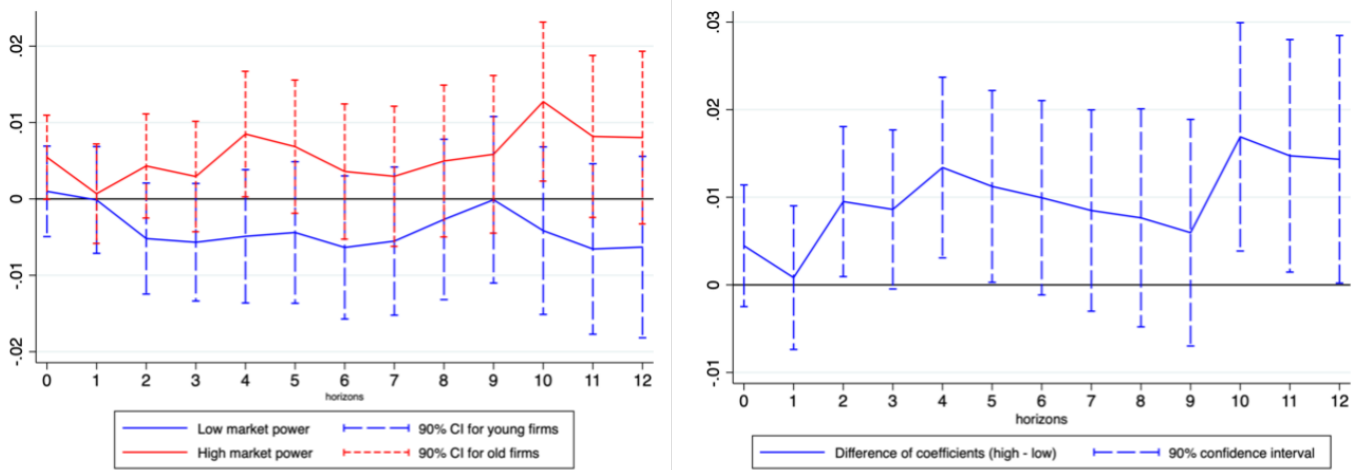

(c) Panel C. Leverage (\%)
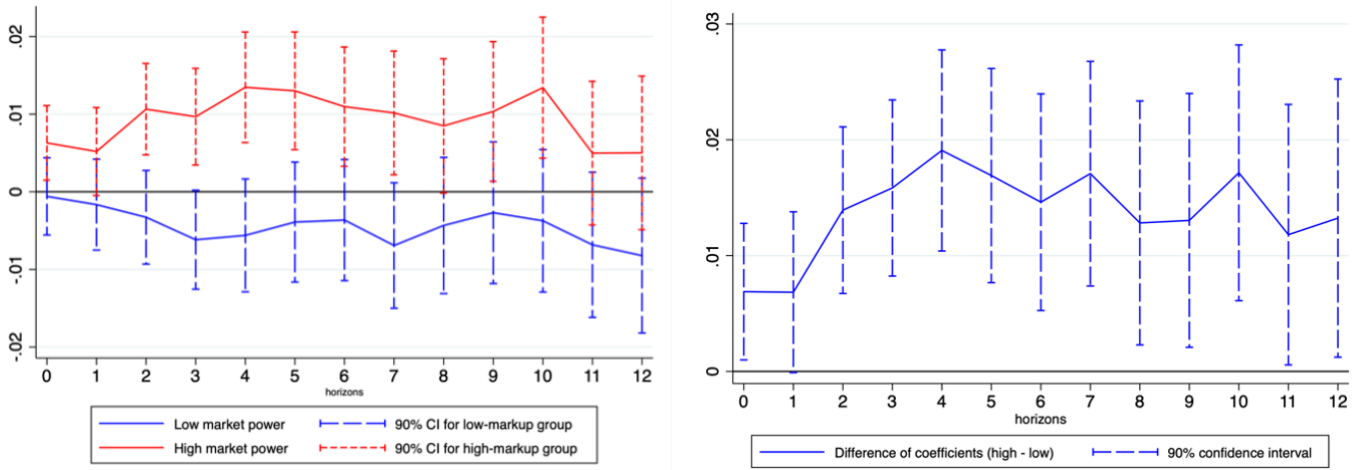

Note: the solid lines indicate the response of real sales to a 100-basis point monetary policy shock; the vertical lines denote 90 percent confidence bands. The $\mathrm{x}$-axis denotes time. $\mathrm{t}=0$ is the quarter of the shock. The estimates are based on equation 7. 
Figure 6 continued: Response of real sales to US monetary policy shocks: high- vs. low-markup firms controlling for interaction between monetary policy shocks and:

(a) Panel A. Liquidity (\%)
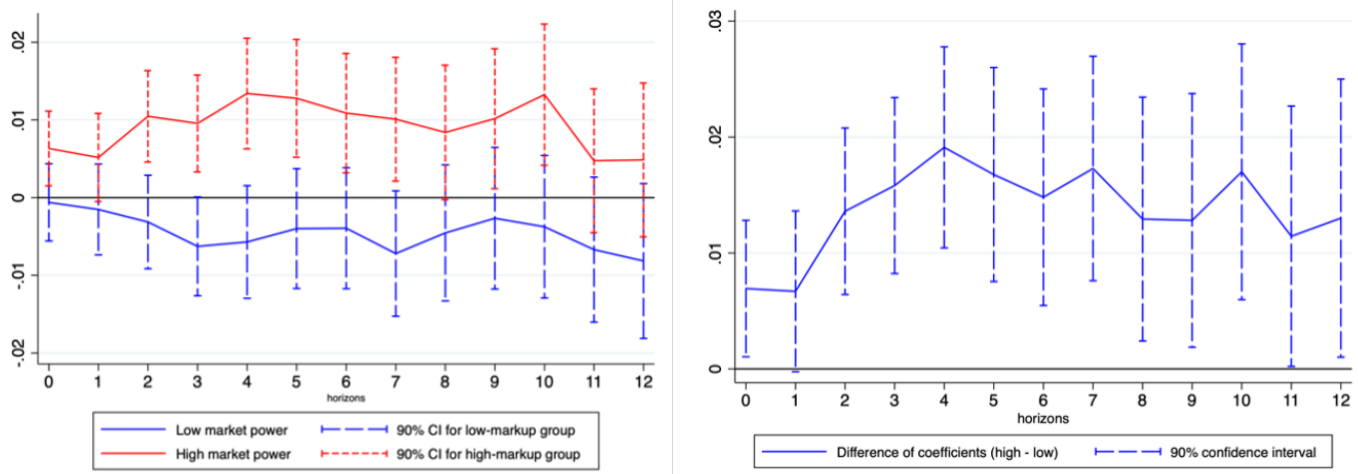

(b) Panel B. Tangibility (\%)
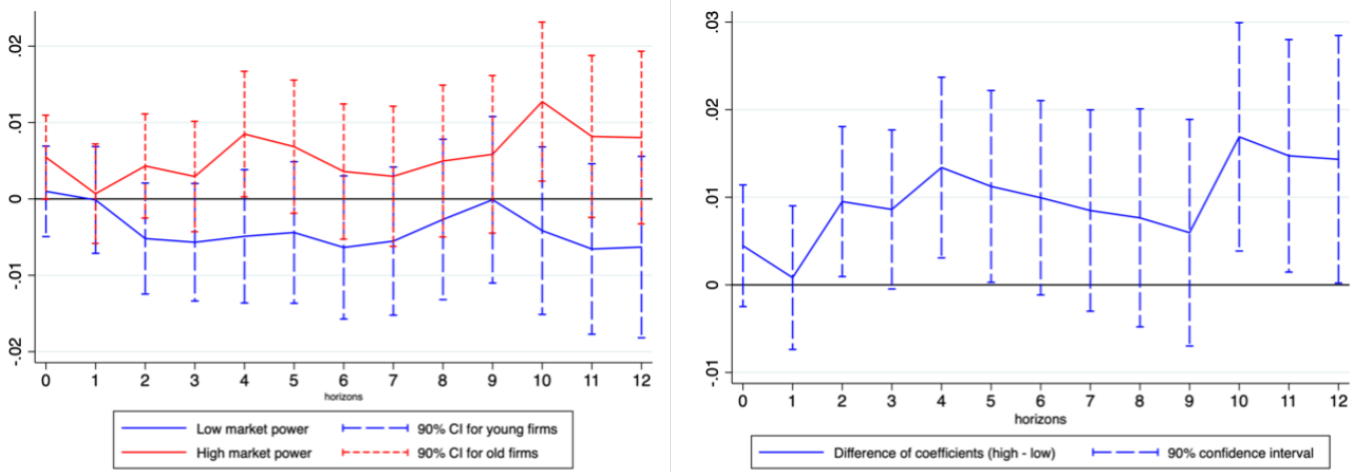

(c) Panel C. Tobin's Q (\%)
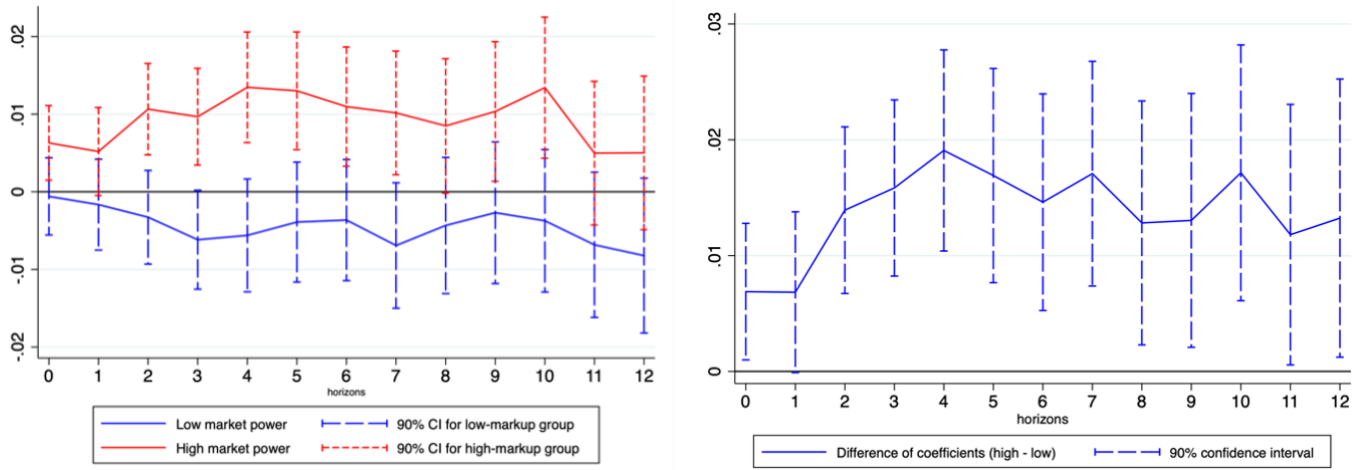

Note: the solid lines indicate the response of real sales to a 100-basis point monetary policy shock; the vertical lines denote 90 percent confidence bands. The $\mathrm{x}$-axis denotes time. $\mathrm{t}=0$ is the quarter of the shock. The estimates are based on equation 7. 
Figure 7: Response of real sales to US monetary policy shocks: high- vs. low-markup firms by size
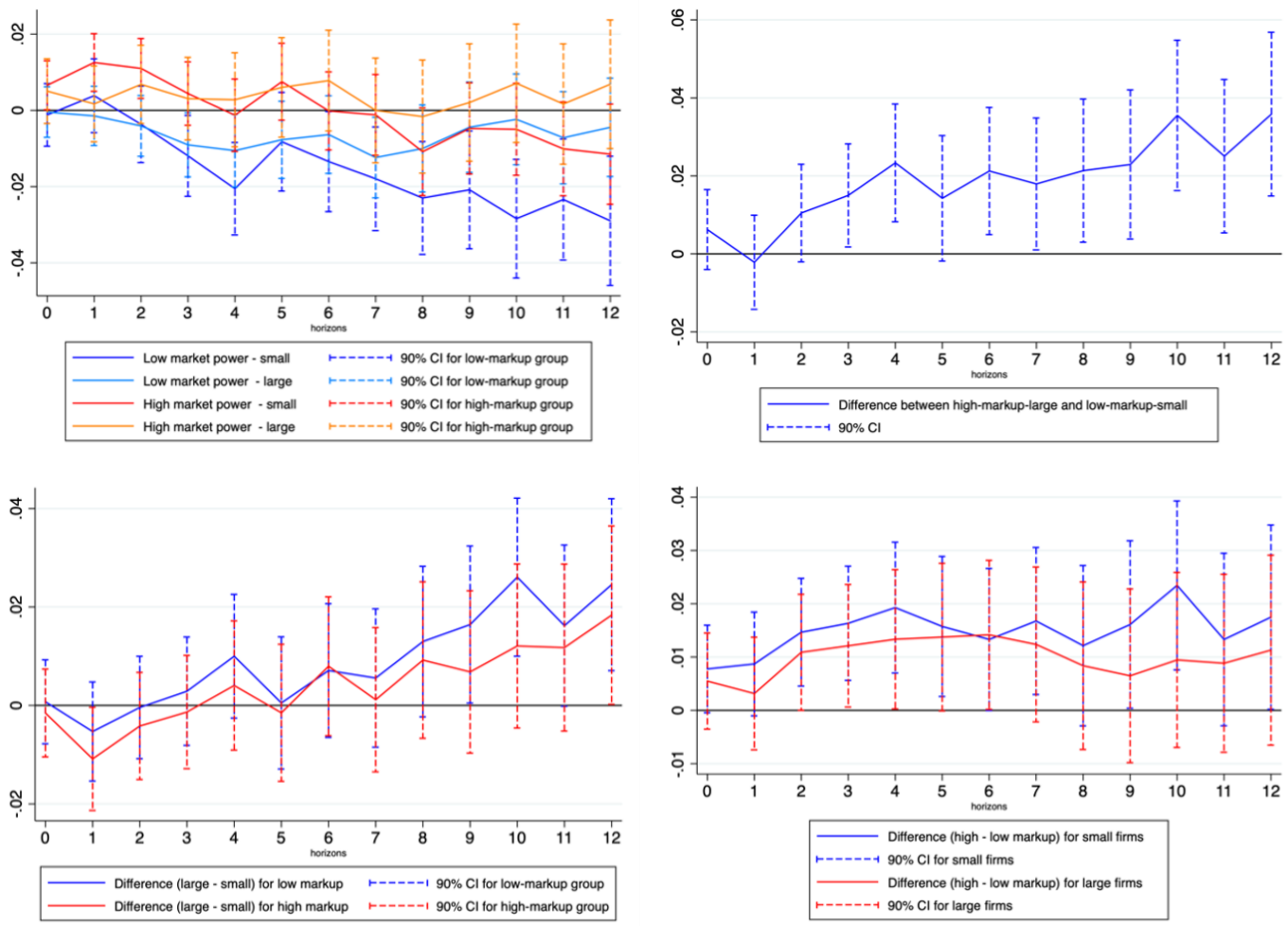

Note: the solid lines indicate the response of real sales to a 100-basis point monetary policy shock; the vertical lines denote 90 percent confidence bands. The $\mathrm{x}$-axis denotes time. $\mathrm{t}=0$ is the quarter of the shock. The estimates are based on equation 8 . 
Figure 8: Response of real sales to US monetary policy shocks: high- vs. low-markup firms by age
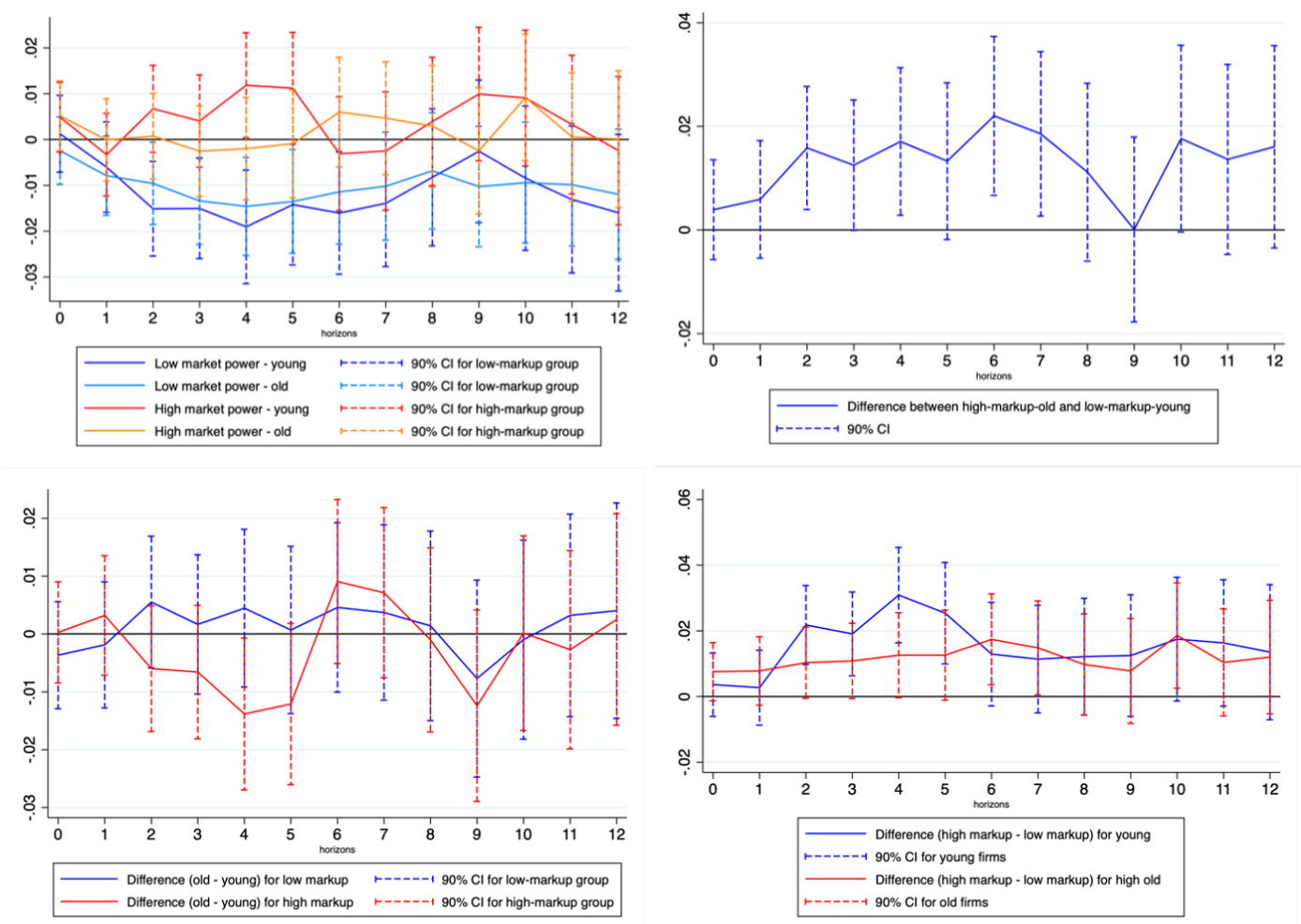

Note: the solid lines indicate the response of real sales to a 100-basis point monetary policy shock; the vertical lines denote 90 percent confidence bands. The $\mathrm{x}$-axis denotes time. $\mathrm{t}=0$ is the quarter of the shock. The estimates are based on equation 8 . 
Figure 9: Response of real sales to monetary policy shocks, panel of advanced countries: high- vs. low-markup firms
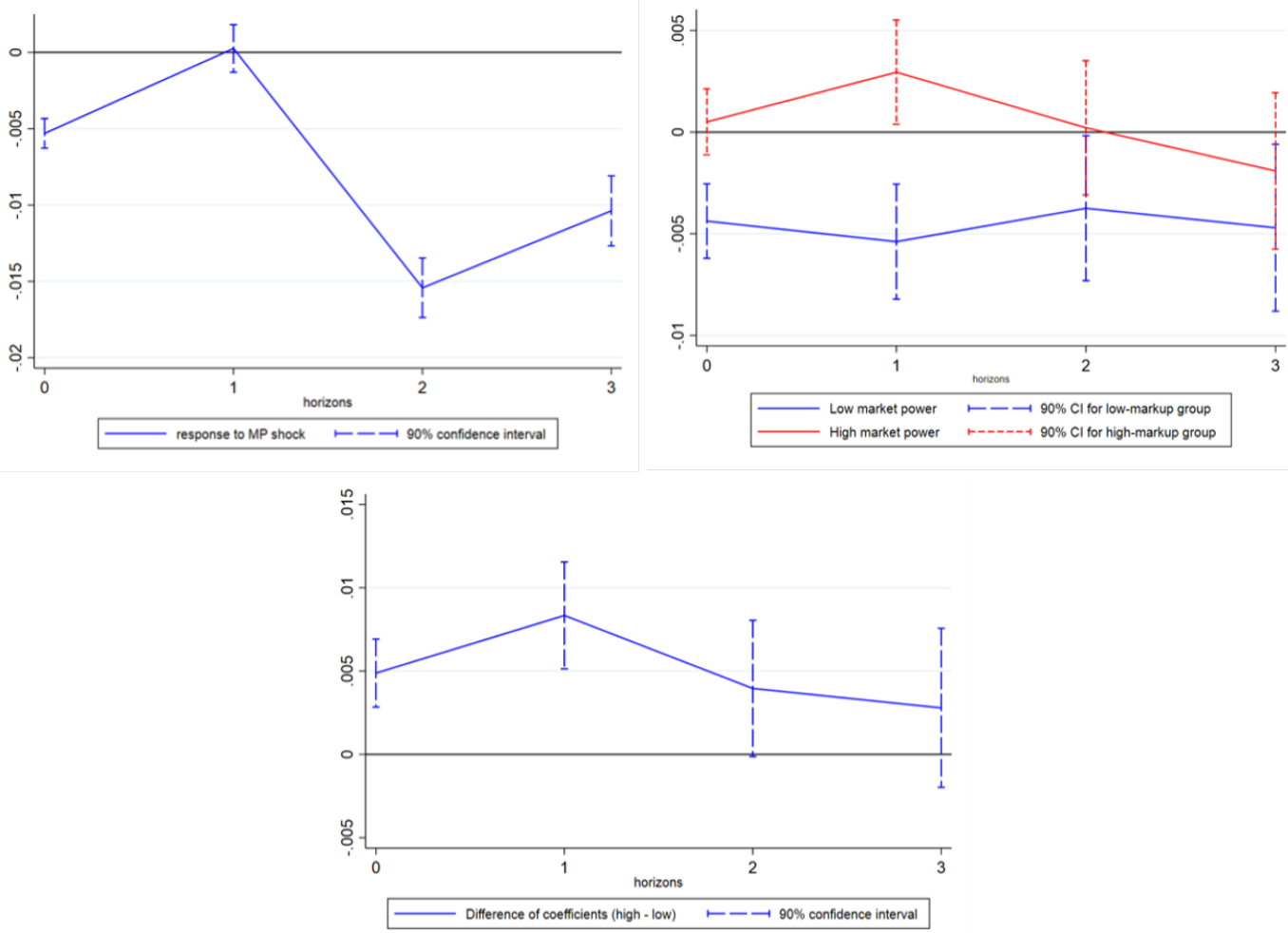

Note: the solid lines indicate the response of real sales to a 100-basis point monetary policy shock; the vertical lines denote 90 percent confidence bands. The $\mathrm{x}$-axis denotes time. $\mathrm{t}=0$ is the year of the shock. The estimates are based on equation 6' 
Figure 10: Response of real sales to monetary policy shocks, panel of advanced countries: high- vs. low-markup firms - controlling for interaction between monetary policy shocks and:

(a) Panel A. Size (\%)
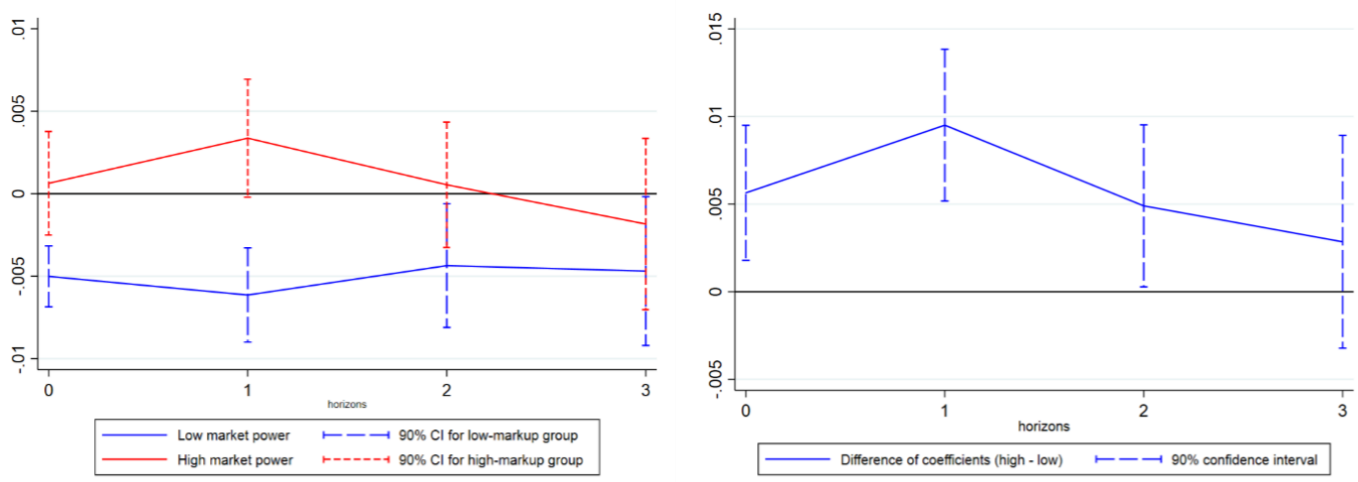

(b) Panel B. Age (\%)
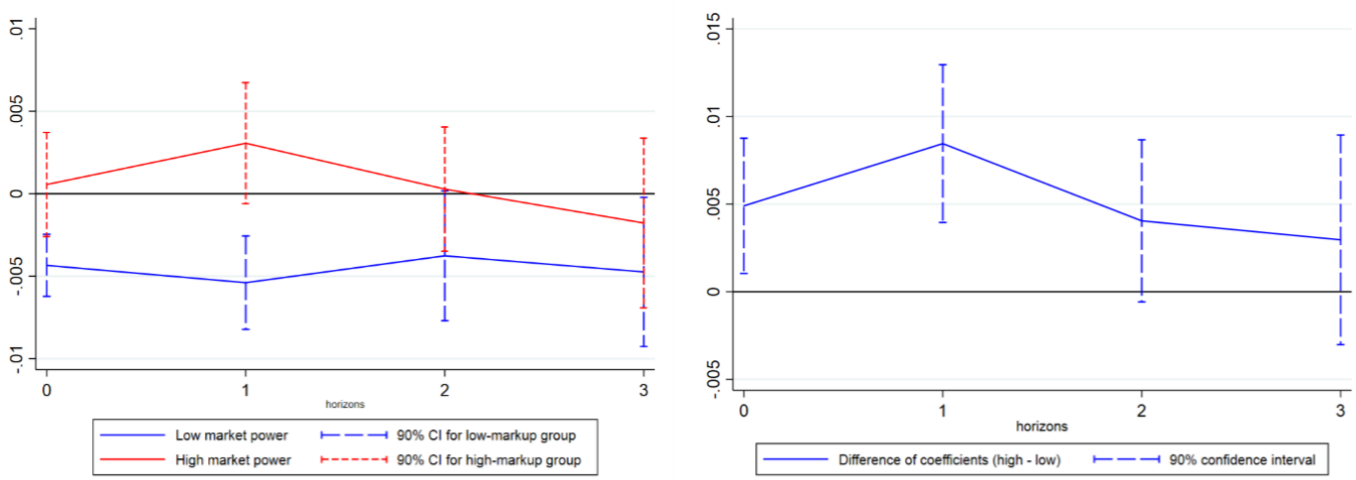

Note: the solid lines indicate the response of real sales to a 100-basis point monetary policy shock; the vertical lines denote 90 percent confidence bands. The $\mathrm{x}$-axis denotes time. $\mathrm{t}=0$ is the year of the shock. The estimates are based on equation $7^{\prime}$. 
Figure 11: Response of real sales to monetary policy shocks, panel of advanced countries: high- vs. low-markup firms by size
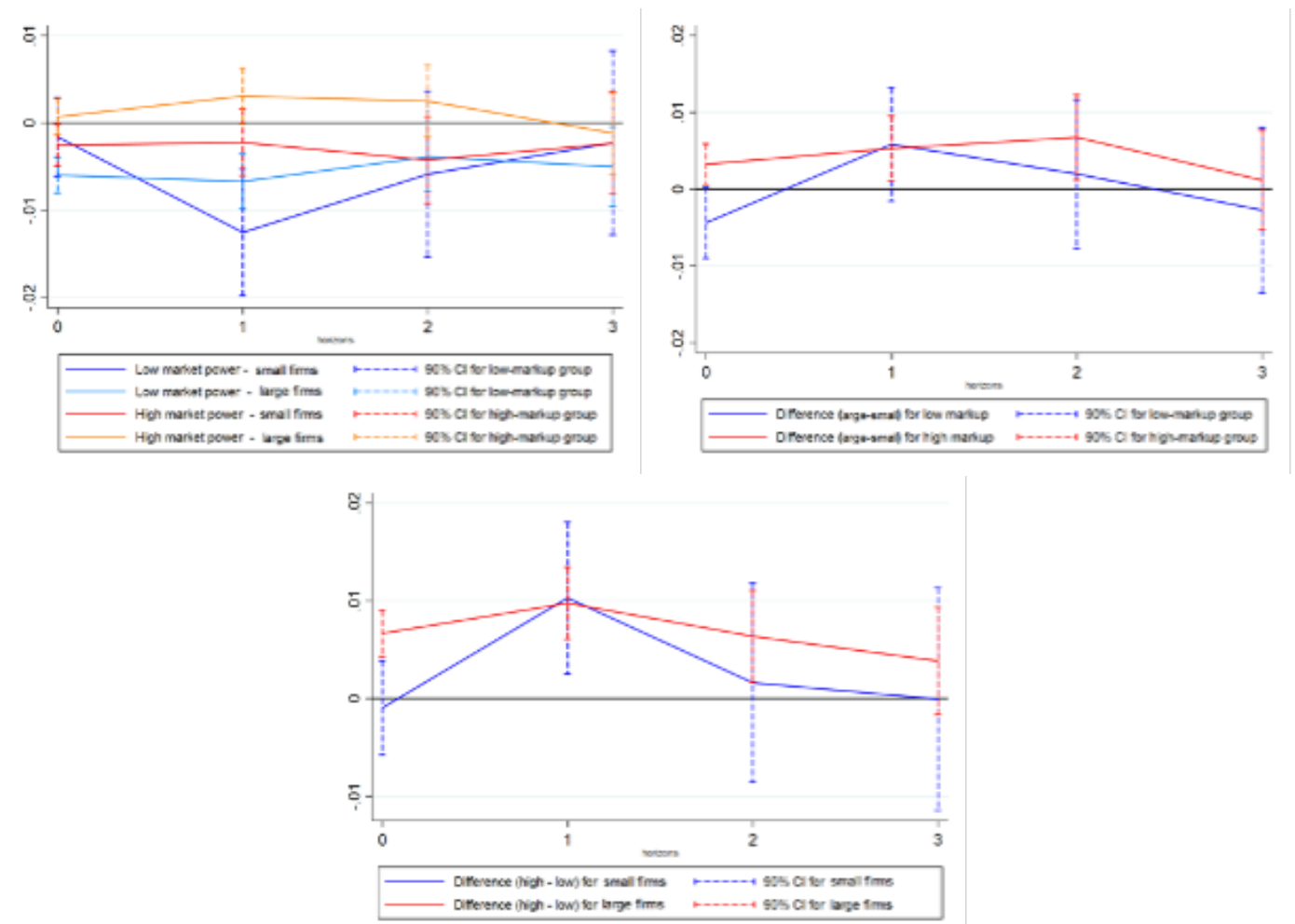

Note: the solid lines indicate the response of real sales to a 100-basis point monetary policy shock; the vertical lines denote 90 percent confidence bands. The $\mathrm{x}$-axis denotes time. $\mathrm{t}=0$ is the year of the shock. The estimates are based on equation 8 '. 
Figure 12: Response of real sales to monetary policy shocks, panel of advanced countries: high- vs. low-markup firms by age
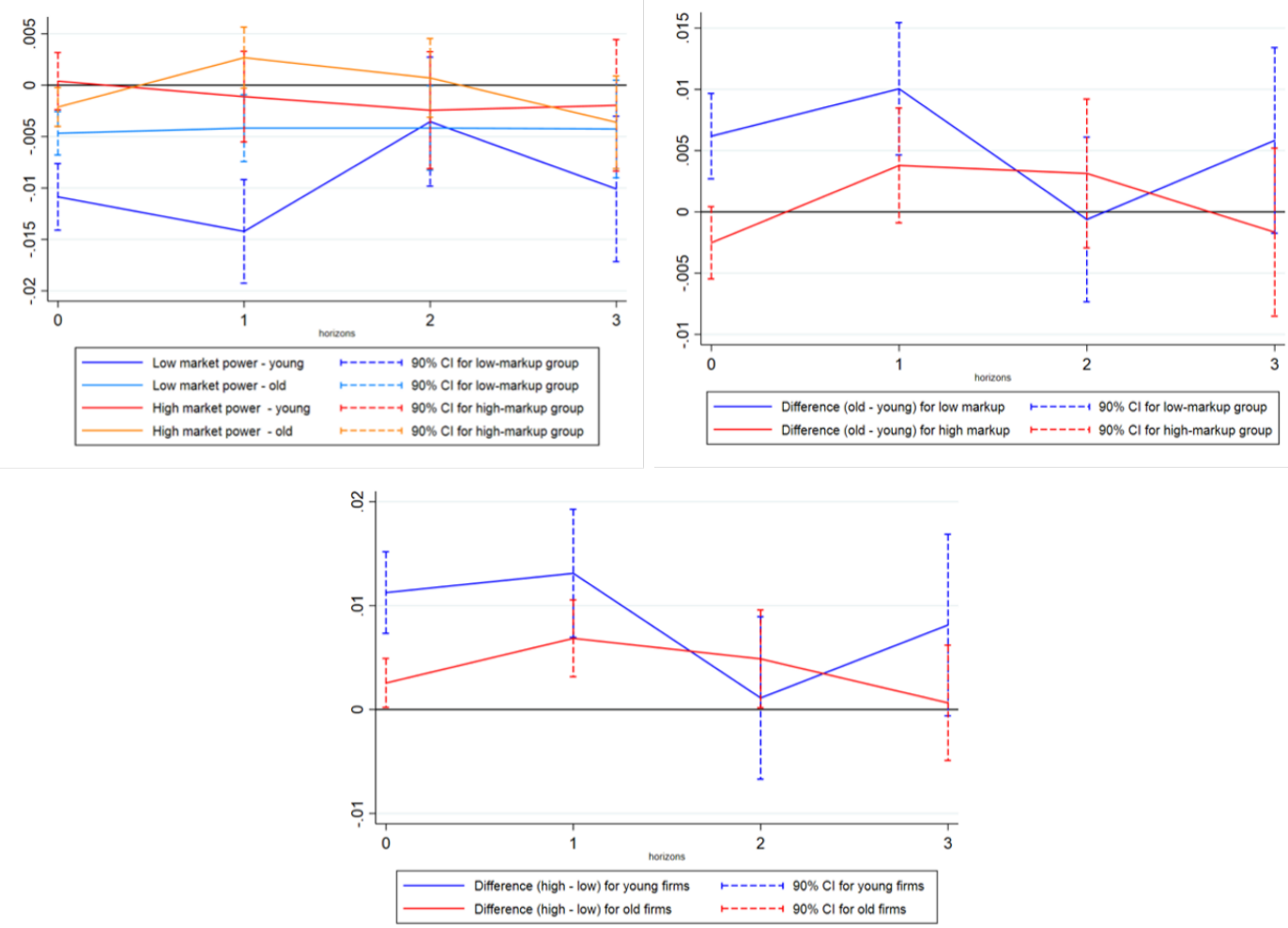

Note: the solid lines indicate the response of real sales to a 100-basis point monetary policy shock; the vertical lines denote 90 percent confidence bands. The $\mathrm{x}$-axis denotes time. $\mathrm{t}=0$ is the year of the shock. The estimates are based on $8^{\prime}$. 


\section{A Appendix}

\section{A.1 Additional empirical analysis}

Figure A.1: Response of real sales and total assets to US monetary policy shocks — restricted sample

(a) Panel A. Real sales (\%)

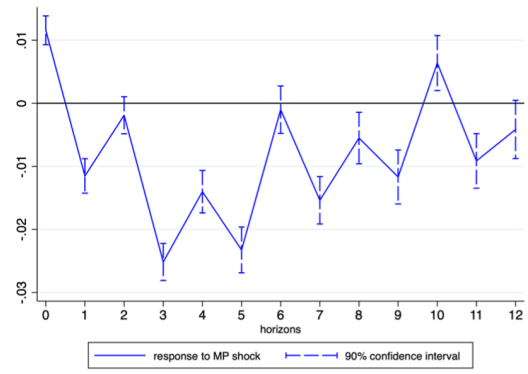

(b) Panel B. Real total assets (\%)

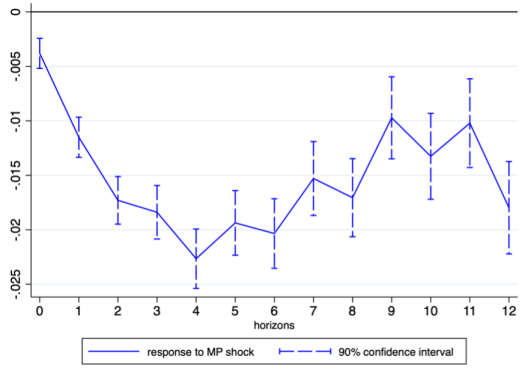

Note: the solid lines indicate the response of real sales (total assets) to a 100-basis point monetary policy shock; the vertical lines denote 90 percent confidence bands. The $\mathrm{x}$-axis denotes time. $\mathrm{t}=0$ is the quarter of the shock. The estimates are based on equation 6 . 
Figure A.2: Response of real sales to US monetary policy shocks for high vs. low values of selected control variables

(a) Panel A. Size (\%)
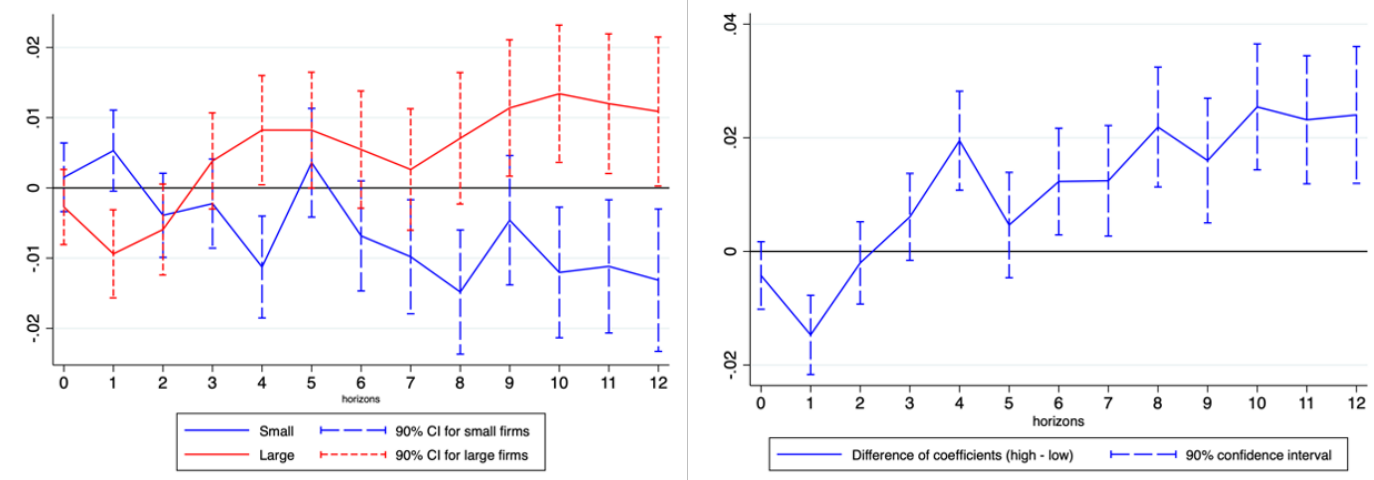

(b) Panel B. Age (\%)
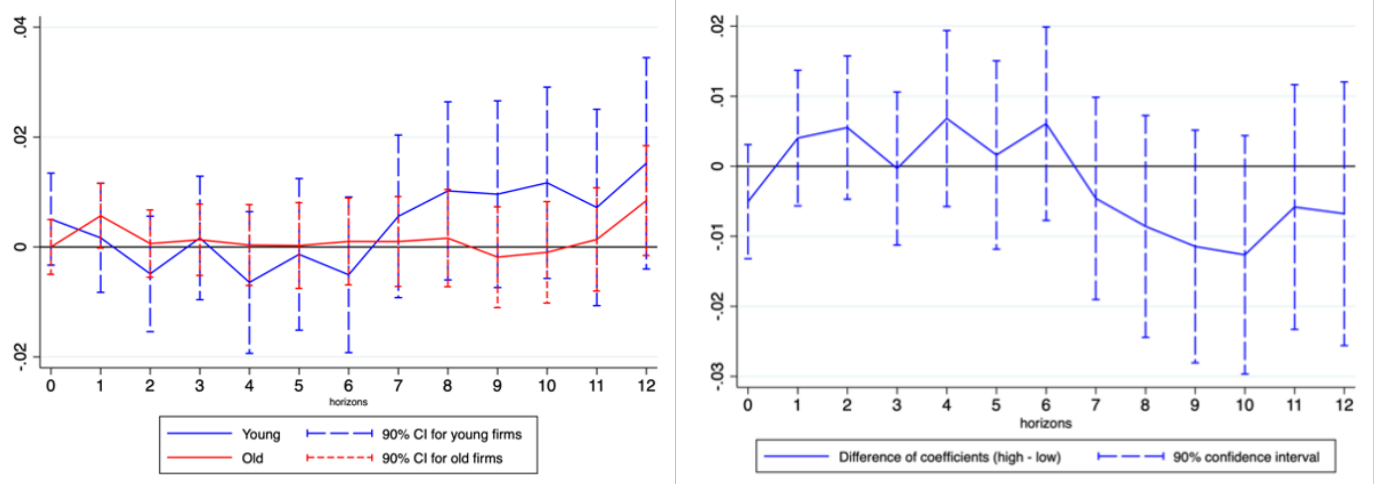

(c) Panel C. Leverage (\%)
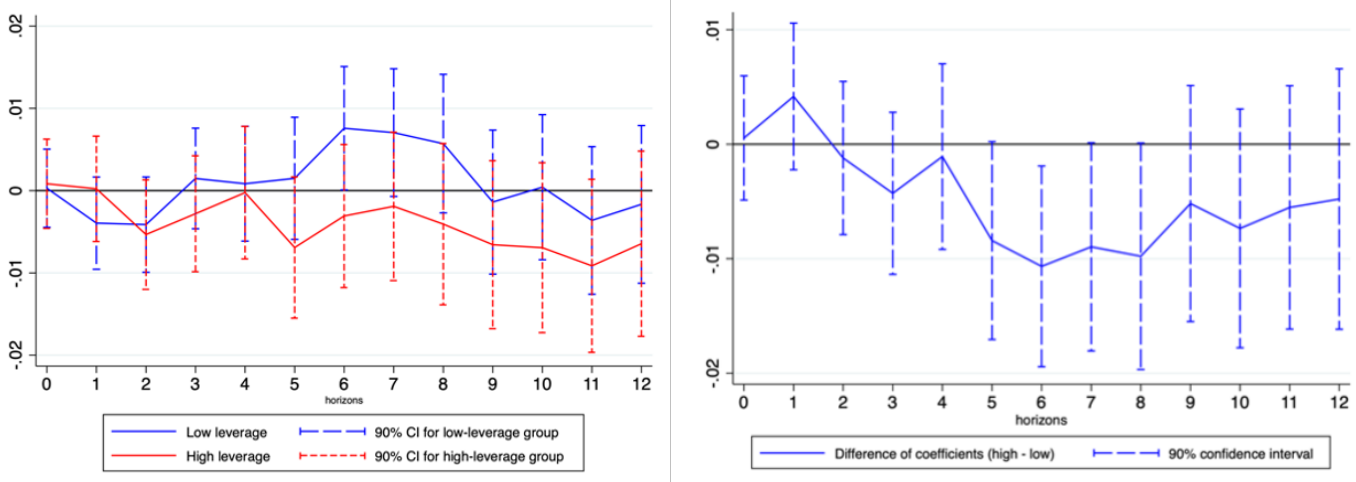

Note: the solid lines indicate the response of real sales to a 100-basis point monetary policy shock; the vertical lines denote 90 percent confidence bands. The $\mathrm{x}$-axis denotes time. $\mathrm{t}=0$ is the quarter of the shock. The estimates are based on equation 6. 
Figure A.3: Response of real sales to US monetary policy shocks: high- vs. low-markup firms by leverage
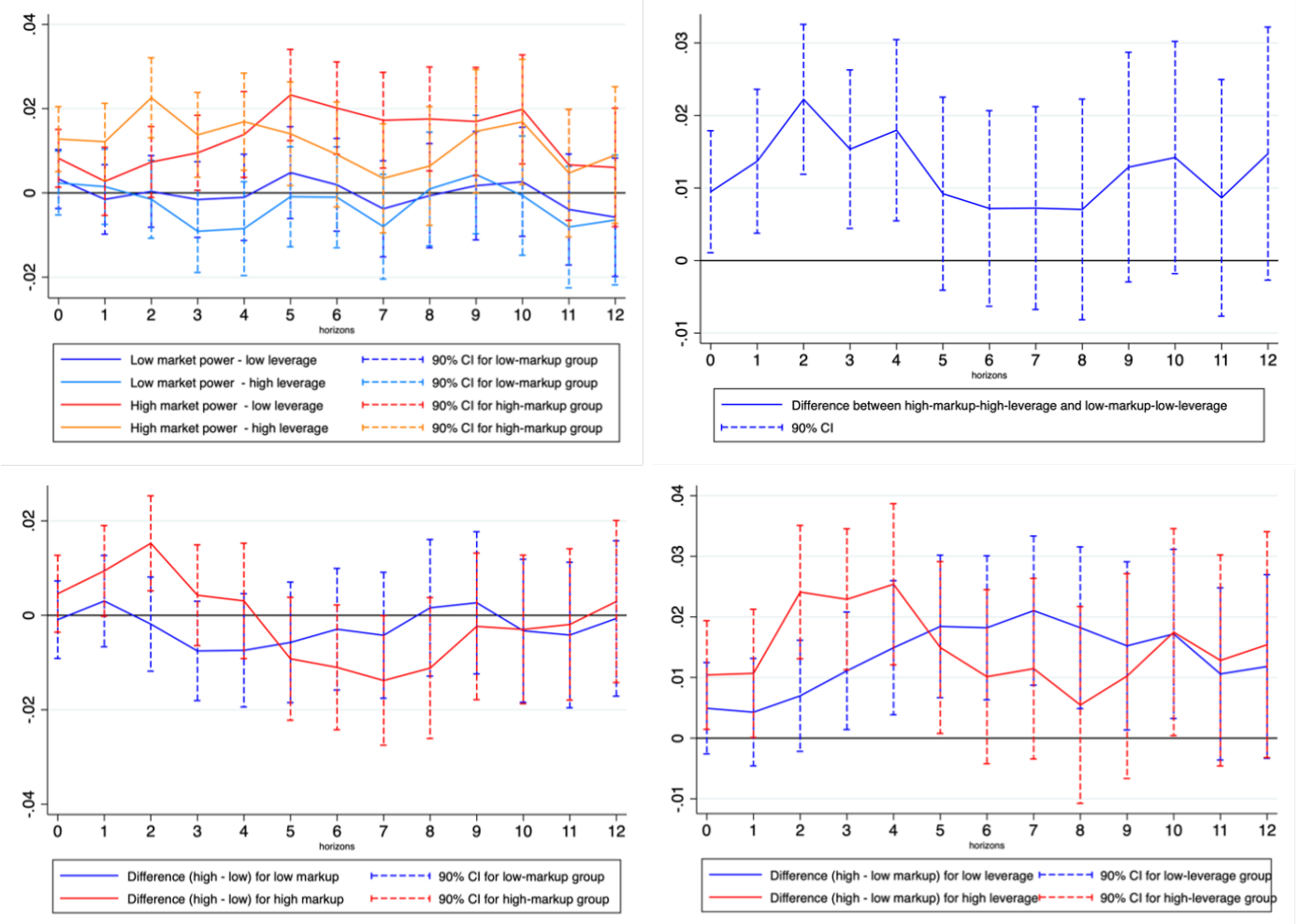

Note: the solid lines indicate the response of real sales to a 100-basis point monetary policy shock; the vertical lines denote 90 percent confidence bands. The $\mathrm{x}$-axis denotes time. $\mathrm{t}=0$ is the quarter of the shock. The estimates are based on equation 8 . 
Figure A.4: Response of real sales to US monetary policy shocks: high- vs. low-markup firms by liquidity
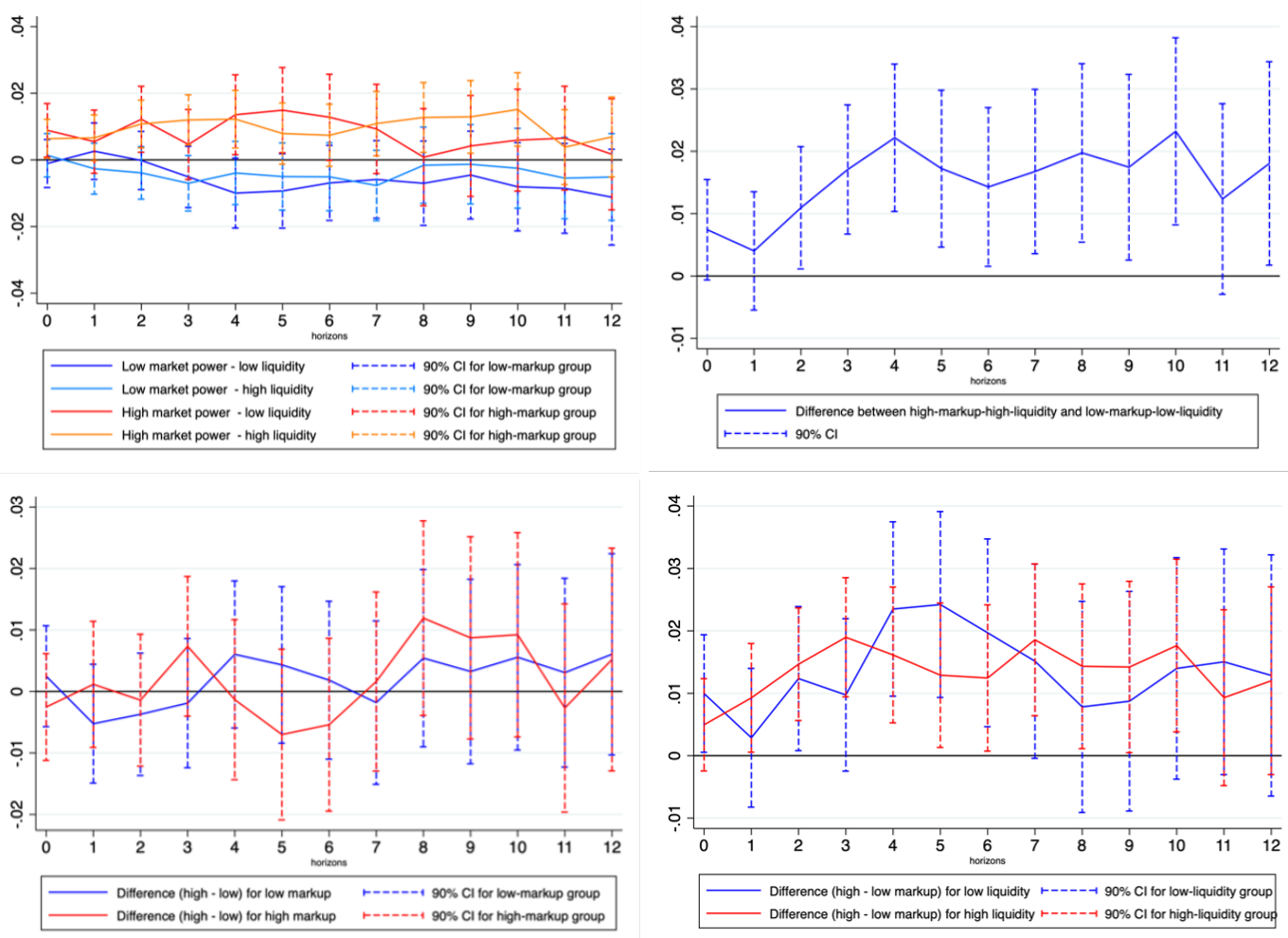

Note: the solid lines indicate the response of real sales to a 100-basis point monetary policy shock; the vertical lines denote 90 percent confidence bands. The $\mathrm{x}$-axis denotes time. $\mathrm{t}=0$ is the quarter of the shock. The estimates are based on equation 7 . 
Figure A.5: Response of real sales to US monetary policy shocks: high- vs. low-markup firms by asset tangibility
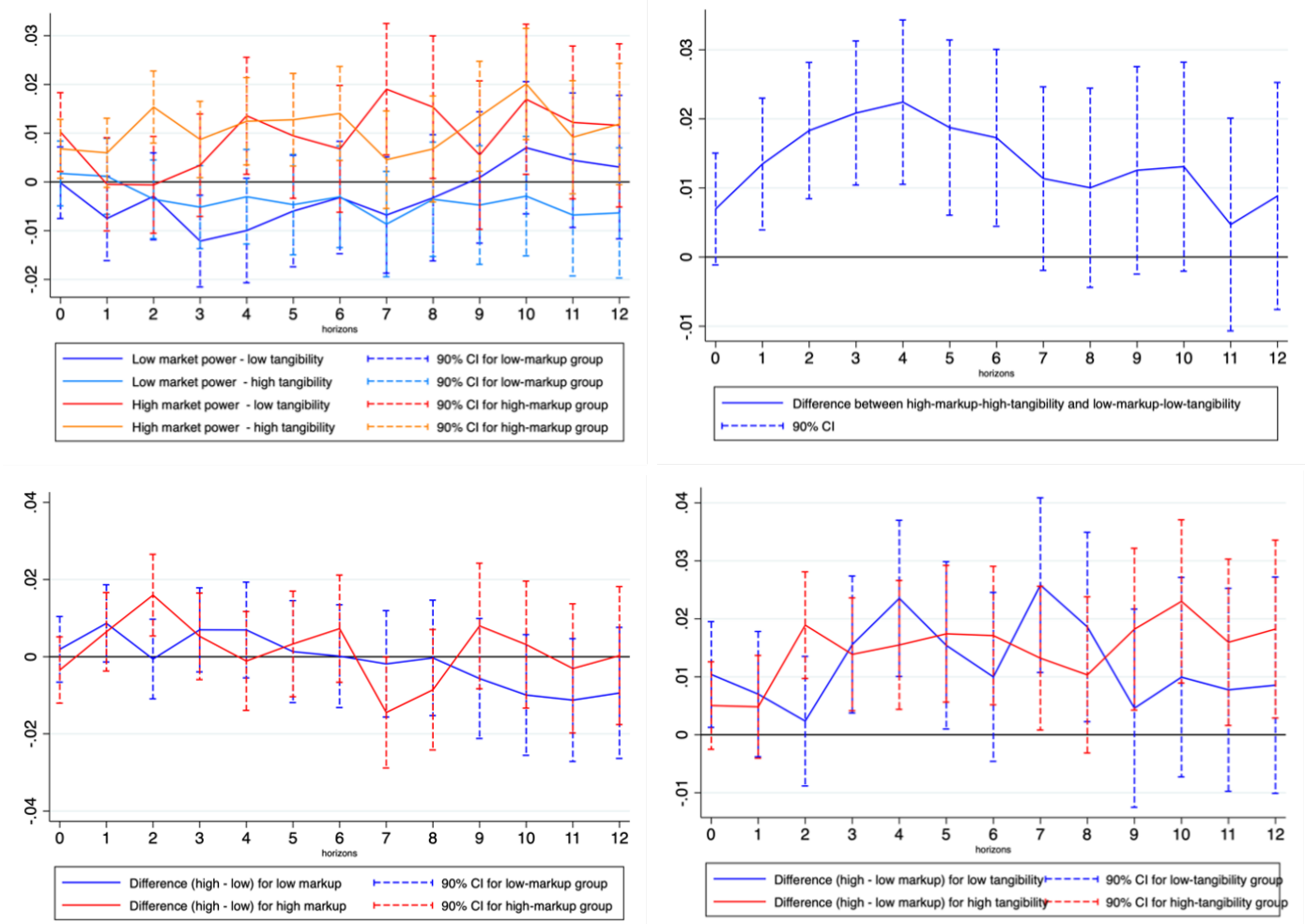

Note: the solid lines indicate the response of real sales to a 100-basis point monetary policy shock; the vertical lines denote 90 percent confidence bands. The $\mathrm{x}$-axis denotes time. $\mathrm{t}=0$ is the quarter of the shock. The estimates are based on equation 8 . 
Figure A.6: Response of real sales to US monetary policy shocks: high- vs. low-markup firms by Tobin’s Q
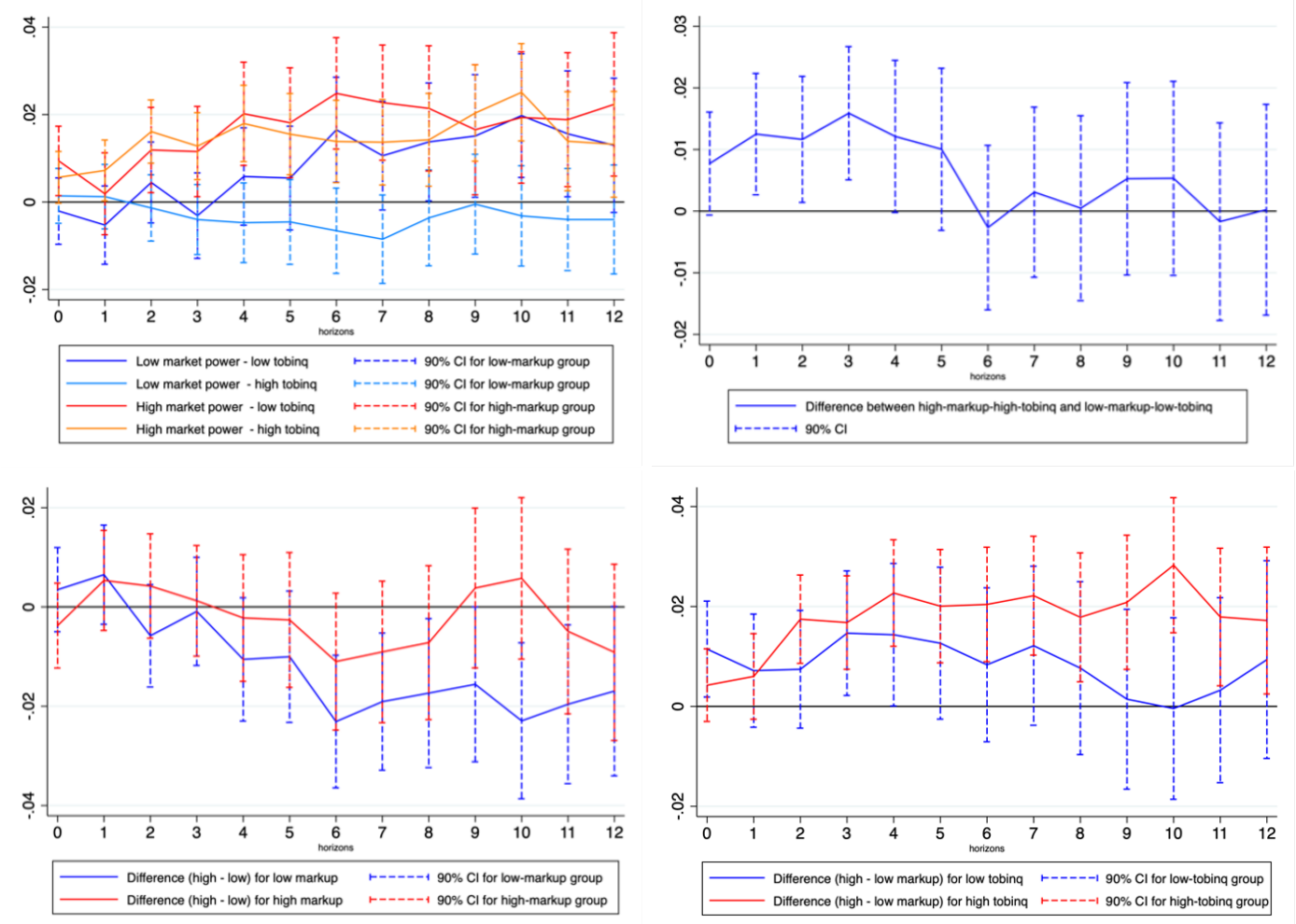

Note: the solid lines indicate the response of real sales to a 100-basis point monetary policy shock; the vertical lines denote 90 percent confidence bands. The $\mathrm{x}$-axis denotes time. $\mathrm{t}=0$ is the quarter of the shock. The estimates are based on equation 8 . 


\section{A.2 Robustness Checks (for Compustat-based analysis)}

Figure A.7: Response of real sales to US monetary policy shock: high- vs. low-markup firms (De Loecker Warzynski) - different bins (based on by-industry median over the whole period)
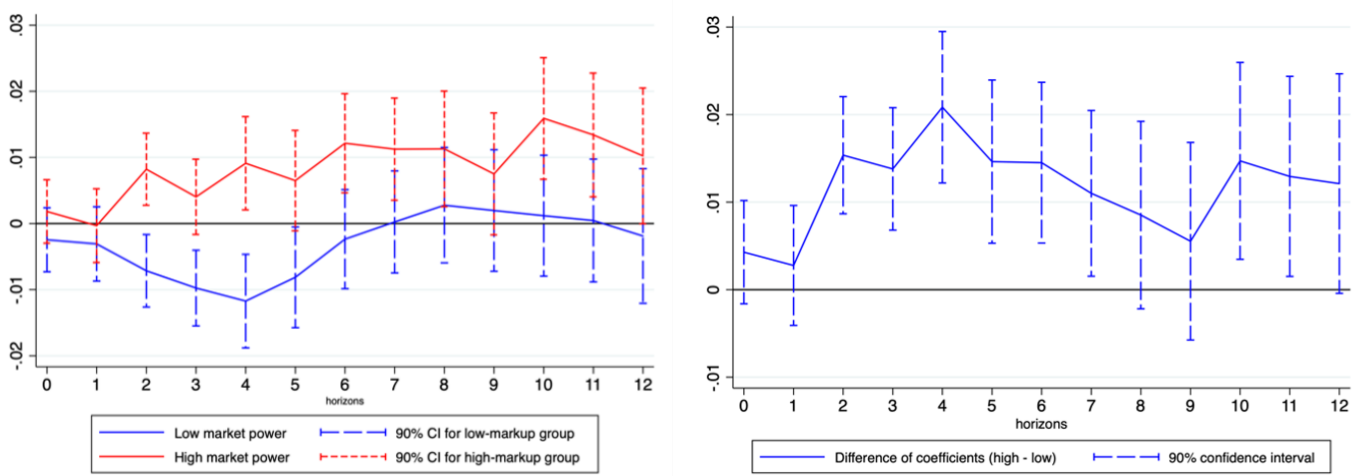

Markup thresholds are built based on median values by industry over the whole period. Then, for each observation, firms are grouped into bins based on their markup level relative to the threshold.

Figure A.8: Response of real sales to US monetary policy shock: high- vs. low-markup firms (Lerner index)
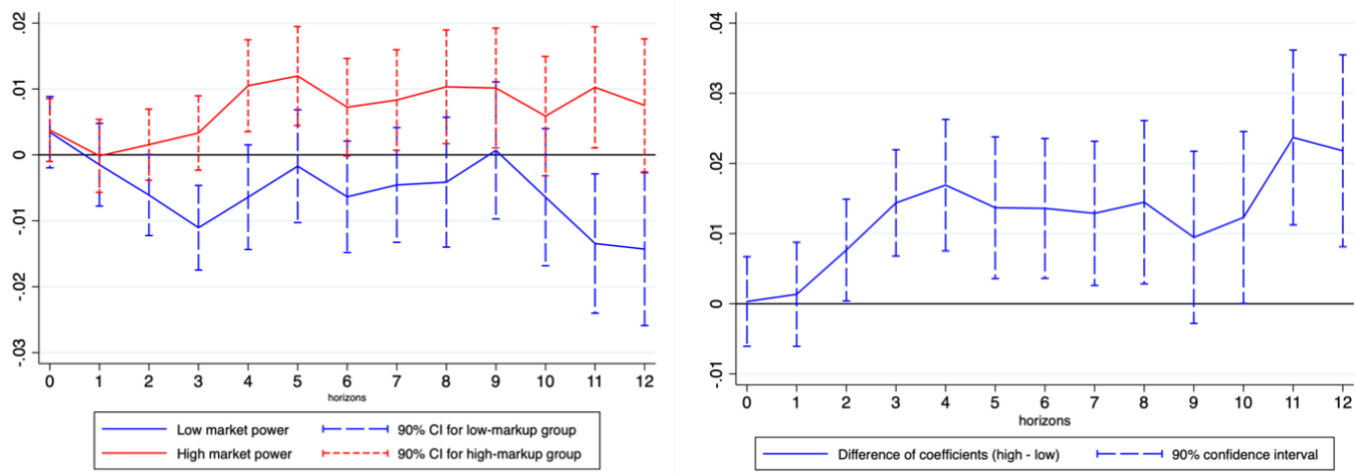

Markup thresholds are built based on median values by industry over the whole period. Then, for each observation, firms are grouped into bins based on their markup level relative to the threshold. 
Figure B.3-1: Response of real sales to US monetary policy shock: high- vs. low-markup firms (Lerner index) by age
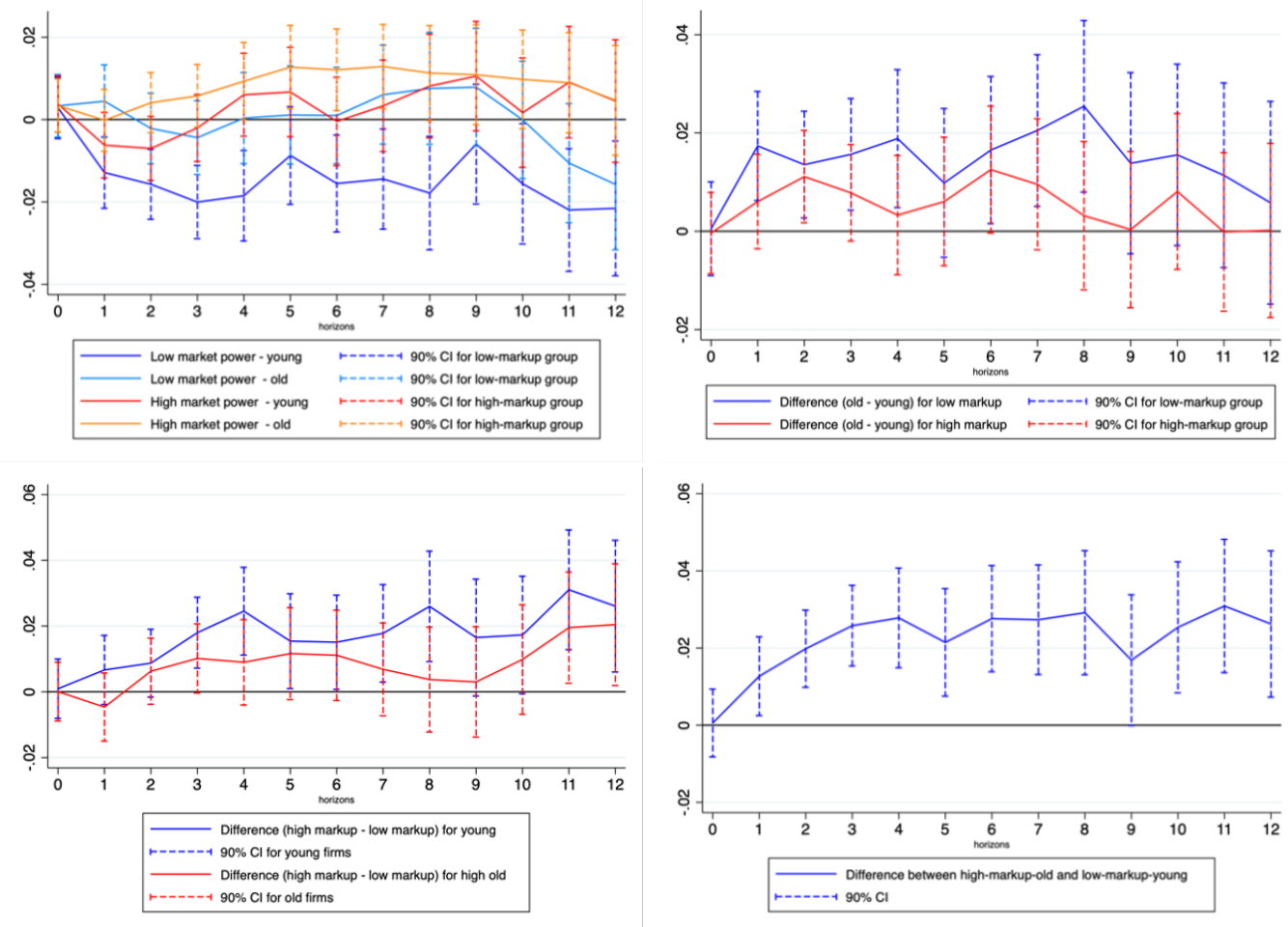

Figure B.3-2: Response of real sales to US monetary policy shock: high- vs. low-markup firms (Lerner index) by size
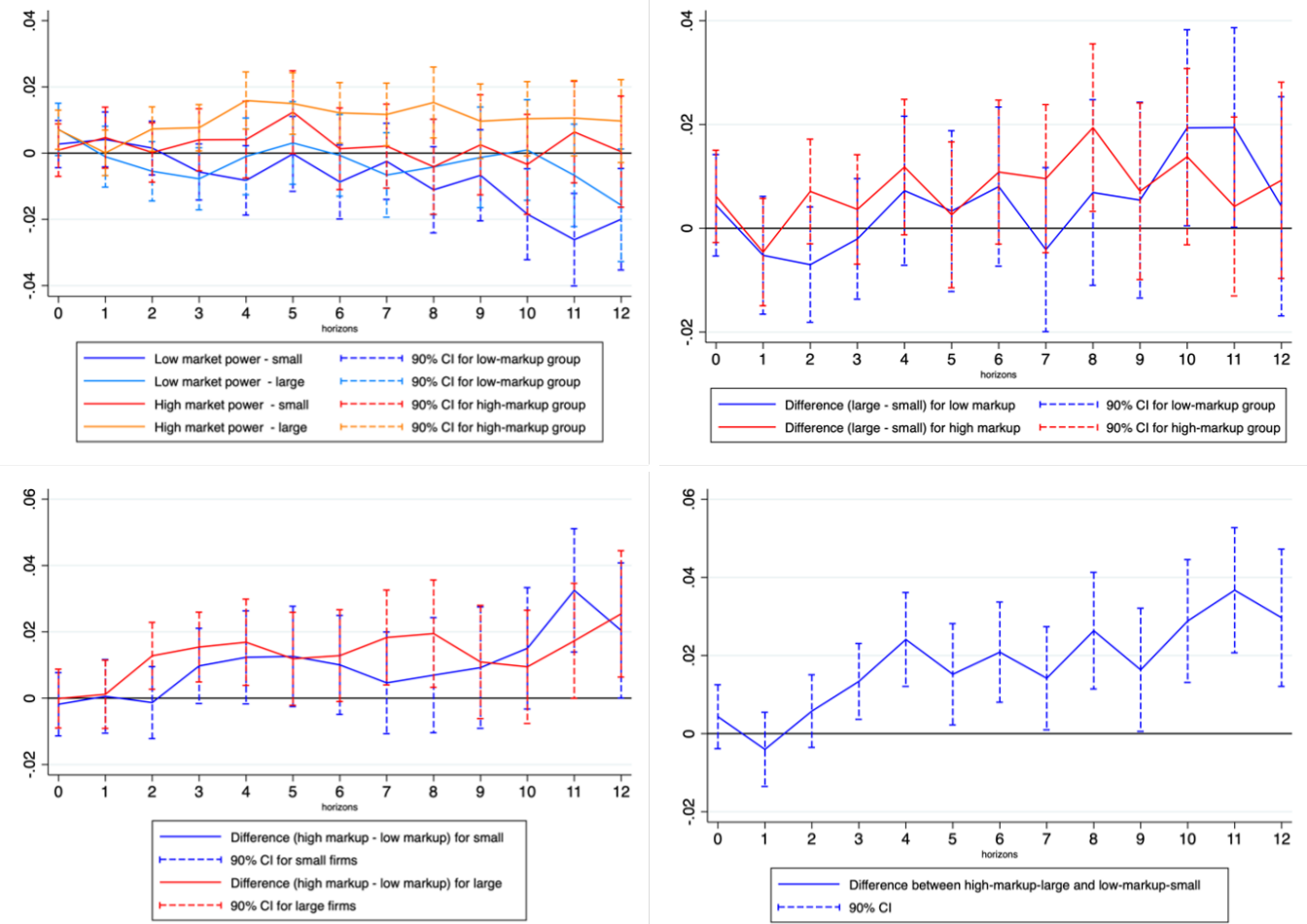


\section{A.3 Robustness Checks (for Orbis-based analysis)}

Figure A.9: Response of real sales to monetary policy shocks, panel of advanced countries: high-vs. low-markup firms - different bins (based on by-industry median value over the whole period)
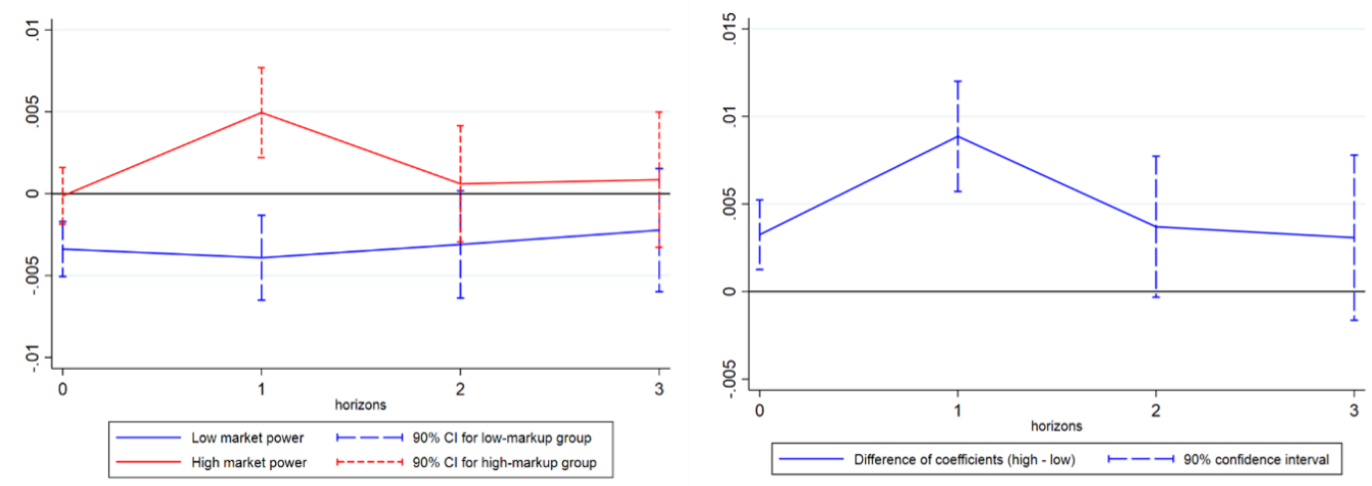

Figure A.10: Response of real sales to monetary policy shocks, panel of advanced countries: high-vs. lowmarkup firms (Lerner index)
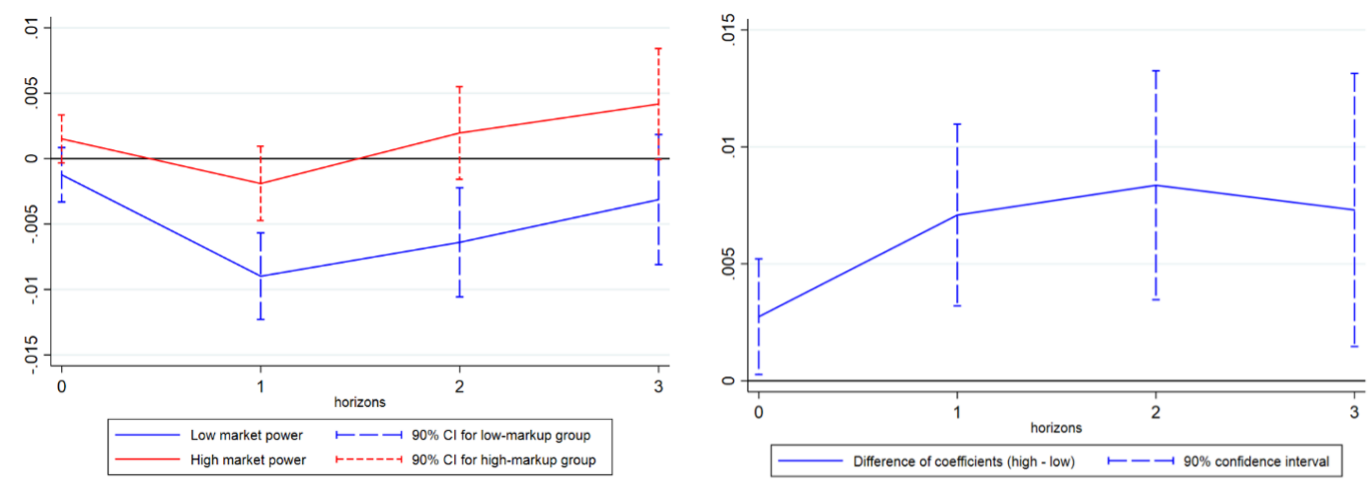

Figure A.11: Response of real sales to monetary policy shocks, panel of advanced countries: high- vs. lowmarkup firms (Lerner index)
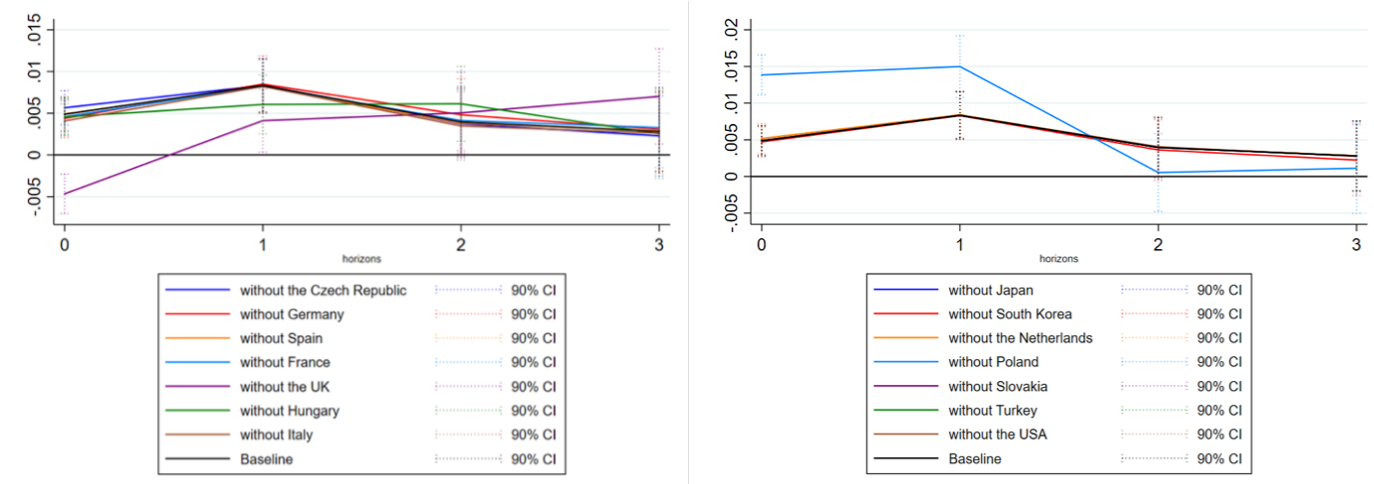


\section{B Theoretical Appendix}

Lemma 9 Given interest rate $R$ and wage $w$, the marginal cost curve $M C(\cdot)$ implied by (1) is:

$$
M C(Q)=\left\{\begin{array}{l}
\left(\frac{R}{\alpha}\right)^{\alpha}\left(\frac{w}{1-\alpha}\right)^{1-\alpha}, Q \leq Q * \\
\frac{1}{1-\alpha} w Q^{\frac{\alpha}{1-\alpha}}\left(\phi(R)+k_{0}\right)^{\frac{-\alpha}{1-\alpha}}
\end{array}\right.
$$

where $Q^{*}$ is given by $Q^{*}(R)=\left(\frac{R}{w} \frac{1-\alpha}{\alpha}\right)^{1-\alpha}\left(\phi(R)+k_{0}\right)$

\section{Proof}

We find the $M C(Q)$ function by solving the firm's minimization problem (10) when the constraint binds and when it does not bind. When the borrowing constraint does not bind, the f.o.c of the firm's problem is given by:

$$
R=\alpha k^{\alpha-1} l^{1-\alpha} \text { and } w=(1-\alpha) k^{\alpha} l^{-\alpha}
$$

After some algebraic manipulation, we can find $k$ and $l$ as a function of $Q$ :

$$
\begin{aligned}
l & =\left(\frac{R}{w} \frac{(1-\alpha)}{\alpha}\right)^{\alpha} Q \\
k & =\left(\frac{w}{R} \frac{\alpha}{(1-\alpha)}\right)^{1-\alpha}
\end{aligned}
$$

And after substituting (14) and (15) into the variable cost function $V C(Q)$ and taking the derivative with respect to $Q$, we find:

$$
M C(Q)=R\left(\frac{w}{R} \frac{\alpha}{1-\alpha}\right)^{1-\alpha}+w\left(\frac{R}{w} \frac{1-\alpha}{\alpha}\right)^{\alpha}
$$

That can be further simplified into:

$$
M C(Q)=\left(\frac{R}{\alpha}\right)^{\alpha}\left(\frac{w}{1-\alpha}\right)^{1-\alpha}
$$

When the borrowing constraint binds, the firm's capital demand $k$ is given by the borrowing constraint:

$$
k=\phi(R)+k_{0}
$$

and labor demand $l$ is found by substituting capital demand $k$ in the expression for output $Q$ :

$$
l=Q^{\frac{1}{1-\alpha}}\left(\phi(R)+k_{0}\right)^{\frac{-\alpha}{1-\alpha}}
$$


After substituting (16) and (17) in the variable cost function $V C(Q)$ and taking the derivative with respect to $Q$, we find the expression for $M C(Q)$ when the borrowing constraint binds:

$$
M C(Q)=\frac{1}{1-\alpha} w Q^{\frac{\alpha}{1-\alpha}}\left(\phi(R)+k_{0}\right)^{\frac{-\alpha}{1-\alpha}}
$$

To find $Q^{*}$, we set equation (17) equal to (18).

Lemma 10 Given the interest rate $r$ - and therefore user cost of capital $R$ :

$$
\frac{d Q^{*}}{d R} \leq 0 \text { if and only if }-\frac{\phi^{\prime}(R)}{\left(\phi(R)+k_{0}\right)} \geq \frac{(1-\alpha)}{R}
$$

Assumption 3 We assume that $\phi(\cdot)$ is such that $-\frac{\phi^{\prime}(R)}{\left(\phi(R)+k_{0}\right)} \geq \frac{(1-\alpha)}{R}$ and hence $Q^{*}$ in (3) is strictly decreasing in $R$.

Proof First, we take the derivative with respect to $R$ from the expression for $Q^{*}(R)$ in equation 3:

$$
\frac{\partial Q^{*}}{\partial R}=(1-\alpha) R^{-\alpha}\left(\frac{1}{w} \frac{1-\alpha}{\alpha}\right)^{1-\alpha}\left(\phi(R)+k_{0}\right)+R^{1-\alpha}\left(\frac{1}{w} \frac{1-\alpha}{\alpha}\right)^{1-\alpha} \phi(R)
$$

This derivative is negative if and only if:

$$
-\frac{\phi^{\prime}(R)}{\left(\phi(R)+k_{0}\right)} \geq \frac{(1-\alpha)}{R}
$$

Lemma 11. A profit-maximizing firm equalizes marginal revenue (MR) and marginal cost $(M C)$ :

$$
M R(q):=\kappa \frac{\xi-1}{\xi} q^{-\frac{1}{\xi}}=M C(q)
$$

whose solution is $p=\frac{\xi}{\xi-1} M C(q)$. The marginal revenue curve is decreasing in $\xi$, implying that - for given output - a high-markup firm has a steeper marginal revenue schedule and responds less to shifts in the marginal cost curve.

\section{Proof}

From the firms' f.o.c. we obtain that $M R(q):=\kappa \frac{\xi-1}{\xi} q^{-\frac{1}{\xi}}$, and the MR's curve slope is given by

$$
\frac{\partial M R}{\partial q}=\kappa \frac{1-\xi}{\xi} q^{-\frac{(1+\xi)}{\xi}}
$$


which is decreasing in $\xi$ as the partial derivative below demonstrates:

$$
\frac{\partial^{2} M R}{\partial q \partial \xi}=\kappa\left(\frac{-2 \xi+1}{\xi^{2}} q^{\frac{-(1+\xi)}{\xi^{2}}}+\frac{1-\xi}{\xi^{4}} q^{\frac{-(1+\xi)}{\xi}} \log (q)\right)
$$

The slope of the MR curve is decreasing in $\xi$, since the partial derivative above is negative when $\xi<1$, implying that high-markup firms, which have a lower $\xi$, have a steeper marginal revenue curve than low-markup firms.

Lemma 12 For a given output $q$, a decline in $r$ leads to a larger fall in the marginal cost on the constrained portion of the MC curve than it does on the unconstrained portion.

\section{Proof}

Formally, we want to show that for a given $Q$, if $r^{2}<r^{1}$ then $M C_{c}^{1}(Q)-M C_{c}^{2}(Q)>M C_{u}^{1}(Q)-M C_{u}^{2}(Q)$, where $M C_{u}^{1}(Q)$ denotes the unconstrained part of the marginal cost curve when the interest rate is $R^{1}$ and $M C_{c}^{1}(Q)$ denotes the constrained part of the marginal cost curve when the interest rate is $R^{1}$. From Lemma 1, these two portions of the marginal cost curve are given by:

$$
\begin{aligned}
M C_{u}^{1}(Q) & =\left(\frac{R^{1}}{\alpha}\right)^{\alpha}\left(\frac{w}{1-\alpha}\right)^{1-\alpha}, Q \leq Q^{1 *} \\
M C_{c}^{1}(Q) & =\frac{1}{1-\alpha} w Q^{\frac{\alpha}{1-\alpha}}\left(\phi\left(R^{1}\right)+k_{0}\right)^{\frac{-\alpha}{1-\alpha}}, \quad Q>Q^{1 *}
\end{aligned}
$$

where $Q^{1 *}$ is the cutoff when the interest rate is equal to $R^{1}$. Analogously, we can let $M C_{u}^{2}(Q)$ and $M C_{c}^{2}(Q)$ denote the unconstrained and constrained portions of the marginal cost curve when the interest rate is $R^{2}$. First, note that the marginal cost curve is strictly increasing in the constrained portion $\left(\frac{\partial M C_{c}}{\partial Q}>0\right)$ and flat in the unconstrained portion $\left(\frac{\partial M C_{u}}{\partial Q}=0\right)$. Second, note that under assumption 1 , the cutoff level under interest rate $R^{2}$ is greater than the cutoff level under interest rate $R^{1}: Q^{2 *}>Q^{1 *}$. Third, note that under the assumption that $\phi(R)$ is decreasing, the difference between the constrained portion of the marginal cost curve is increasing in $Q$, $\frac{\partial\left(M C_{c}^{1}(Q)-M C_{c}^{2}(Q)\right)}{\partial Q}>0$. Now, we are ready to prove our Lemma under two cases depending on whether the firm is ex ante and ex post constrained (case 1) or whether it is ex ante constrained and ex post unconstrained (case 2).

Case 1: $Q>Q^{2 *}>Q^{1 *}$

First, since the constrained portion of the marginal cost curve is increasing in $Q$, the difference between the two constrained marginal cost functions is increasing in $Q, \frac{\partial\left(M C_{c}^{1}(Q)-M C_{c}^{2}(Q)\right)}{\partial Q}>0$. Second, since the constrained marginal cost curve is increasing in $\mathrm{Q}$, the marginal cost in $Q^{2 *}$ is greater than in $Q^{1 *},\left(M C_{c}^{1}\left(Q^{2 *}\right)>M C_{c}^{1}\left(Q^{1 *}\right)\right)$. Last by construction, the unconstrained and the constrained portions of the marginal cost curve are equal in $Q^{*}$. These three observations lead to: $M C_{c}^{1}(Q)-M C_{c}^{2}(Q)>M C_{c}^{1}\left(Q^{2 *}\right)-M C_{c}^{2}\left(Q^{2 *}\right)>M C_{c}^{1}\left(Q^{1 *}\right)-M C_{c}^{2}\left(Q^{2 *}\right)=$ $M C_{u}^{1}(Q)-M C_{u}^{2}(Q)$

Case 2: $Q^{2 *}>Q>Q^{1 *}$ 
In this case, the firm is initially operating on the constrained portion of the marginal cost curve, but it becomes unconstrained after the interest rate decline. We want to show that the shift on the marginal cost curve is then greater than it would be when the firm is always unconstrained. First, note that since the constrained portion of the marginal cost curve is increasing in $Q, M C_{c}^{1}(Q)>M C_{c}^{1}\left(Q^{1 *}\right)$. Second, note that by definition the unconstrained and constrained portions of the marginal cost curves are equal in $Q^{1 *}$, implying $M C_{c}^{1}\left(Q^{1 *}\right)=M C_{u}^{1}(Q)$. Therefore:

$$
M C_{c}^{1}(Q)-M C_{u}^{2}(Q)>M C_{c}^{1}\left(Q^{1 *}\right)-M C_{u}^{2}(Q)=M C_{u}^{1}(Q)-M C_{u}^{2}(Q)
$$

Lemma 13 If high-and low-markup firms are both financially unconstrained ex ante and ex post, and have the same initial output level $q^{*}$, then a reduction in the interest rate triggers a larger output response for the low-markup firm $\left(q^{L}>q^{H}\right)$

\section{Proof}

Since both firms operate ex-ante and ex-post on the unconstrained portion of the marginal cost curve, we can explicitly solve for $q$ by equalizing marginal revenue to marginal cost on the unconstrained part of the marginal cost curve, $M R(q)=M C_{u}(q)$. After some simple algebraic manipulation, we find:

$$
q=\kappa^{\xi}\left(\frac{\xi-1}{\xi}\right)^{\xi}\left[\left(\frac{\alpha}{r}\right)^{\alpha}\left(\frac{1-\alpha}{w}\right)^{(1-\alpha)}\right]^{\xi} .
$$

Taking the derivative with respect to $\xi$, we find:

$$
\frac{\partial q}{\partial \xi}=\kappa^{\xi}\left(\frac{\xi-1}{\xi}\right)^{\xi}\left[\left(\frac{\alpha}{r}\right)^{\alpha}\left(\frac{1-\alpha}{w}\right)^{(1-\alpha)}\right]^{\xi}\left[\log (\kappa)+\log \left(\left(\frac{\alpha}{r}\right)^{\alpha}\left(\frac{1-\alpha}{w}\right)^{1-\alpha}\right)+\log \left(\frac{\xi-1}{\xi}\right)+\frac{1}{\xi-1}\right]>0
$$

Where the derivative above is positive for a sufficient large $\mathcal{k}$, formally it is sufficient that $\kappa>\left(\frac{r}{\alpha}\right)^{\alpha}\left(\frac{w}{1-\alpha}\right)^{(1-\alpha)} \frac{\xi}{\xi-1}$. This derivative implies that a high-markup firm, which has a lower $\xi$, produces less output than a low-markup firm, all else equal. Second, note that output is decreasing in the interest rate $\mathrm{r}$ :

$$
\frac{\partial q}{\partial r}=\kappa^{\xi}\left(\frac{\xi-1}{\xi}\right)^{\xi}\left[(\alpha)^{\alpha}\left(\frac{1-\alpha}{w}\right)^{(1-\alpha)}\right]^{\xi}\left(\frac{1}{r}\right)^{\alpha \xi-1}(-\alpha \xi)<0
$$

higher interest rates reduce the output produced by unconstrained firms. Next, we can take the cross-derivative 
with respect to $\xi$ to show that a decline in the interest rate increases output more for low-markup firms:

$$
\begin{aligned}
\frac{\partial q}{\partial \xi \partial r} & =\kappa^{\xi}\left(\frac{\xi-1}{\xi}\right)^{\xi}\left[\log (\kappa)+\log \left(\left(\frac{\alpha}{r}\right)^{\alpha}\left(\frac{1-\alpha}{w}\right)^{(1-\alpha)}\right)\right. \\
& \left.+\log \left(\frac{\xi-1}{\xi}\right)+\frac{1}{\xi-1}\right]\left[\left(\frac{1-\alpha}{w}\right)^{(1-\alpha) \xi}\right]\left(\frac{1}{r}\right)^{\alpha \xi-1}(-\alpha \xi) \\
& +\kappa^{\xi}\left(\frac{\xi-1}{\xi}\right)^{\xi}\left[\left(\frac{\alpha}{r}\right)^{\alpha}\left(\frac{1-\alpha}{w}\right)^{(1-\alpha)}\right]^{\xi}\left[-\frac{\alpha}{r}\right]<0
\end{aligned}
$$

where the derivative above is negative using the same sufficient condition regarding $\mathcal{\kappa}$, formally it is sufficient that $\kappa>\left(\frac{r}{\alpha}\right)^{\alpha}\left(\frac{w}{1-\alpha}\right)^{(1-\alpha)} \frac{\xi}{\xi-1}$.

Lemma 14 If high-and low-markup firms are both financially unconstrained and have the same output level $q^{*}$ ex-ante, then if only one firm becomes constrained after a decline in the interest rate, this firm will be the low-markup firm.

Proof This follows from Lemma 13 and the fact that $\frac{\partial q}{\partial \xi \partial r}$ in equation (20) is negative. Since the low-markup firm's output is more responsive to a given decline in the interest rate, this firm will always become constrained before the high-markup firm is.

Lemma 15 If high-and low-markup firms are both financially constrained both ex-ante and ex-post, and have the same initial output level $q^{*}$, then a reduction on the interest rate triggers a larger output response for the low-markup firm $\left(q^{L}>q^{H}\right)$.

\section{Proof}

Since both firms are operating on the constrained part of the marginal cost curve ex-ante and ex-post, we can solve for q by equalizing marginal revenue to marginal cost on the constrained part of the marginal cost curve $M R(q)=M C_{c}(q)$. After some simple algebraic manipulation, we find:

$$
q=\left(\kappa \frac{1-\alpha}{w} \frac{\xi-1}{\xi}\right)^{\frac{\xi(1-\alpha)}{\alpha \xi+(1-\alpha)}}\left(\phi(R)+k_{0}\right)^{\frac{\alpha \xi}{\alpha \xi+(1-\alpha)}}
$$

Taking the derivative of $q$ with respect to $\xi$ gives the following:

$$
\begin{aligned}
\frac{\partial q}{\partial \xi} & =\left(\kappa \frac{1-\alpha}{w} \frac{\xi-1}{\xi}\right)^{\frac{(1-\alpha) \xi}{\alpha \xi+(1-\alpha)}}\left(\phi(R)+k_{0}\right)^{\frac{\alpha \xi}{\alpha \xi+(1-\alpha)}}\left[\left(\frac{(1-\alpha)}{\alpha \xi+(1-\alpha)}\right)\right. \\
& \left.+\log \left(\kappa \frac{1-\alpha}{w} \frac{\xi-1}{\xi}\right)\left(\frac{(1-\alpha)^{2}}{(\alpha \xi+(1-\alpha))^{2}}\right)+\log \left(\phi(R)+k_{0}\right)\left(\frac{\alpha(1-\alpha)}{(\alpha \xi+(1-\alpha))^{2}}\right)\right]>0
\end{aligned}
$$

To guarantee that the quantity produced decreases with the firm's market power, we need that the derivative of $\mathrm{q}$ with respect to $\xi$ be positive, which is obtained when all terms between the brackets are positive. A 
sufficient condition is that the initial stock of capital $k_{0}$ and constant $\kappa$ are sufficient large, it is sufficient that $\kappa>\frac{w}{1-\alpha} \frac{\xi}{\xi-1}$ and $k_{0}>1-\phi(R)$.

Second, note that output produced is decreasing in the interest rate $r$, and the derivative is given by:

$$
\frac{\partial q}{\partial r}=\left(\kappa \frac{1-\alpha}{w} \frac{\xi-1}{\xi}\right)^{\frac{\xi(1-\alpha)}{\alpha \xi+(1-\alpha)}}\left(\phi(R)+k_{0}\right)^{\frac{\alpha \xi}{\alpha \xi+(1-\alpha)}-1} \frac{\alpha \xi}{\alpha \xi+(1-\alpha)} \phi^{\prime}(R)<0 .
$$

This derivate is negative under the assumption that $\phi(\cdot)$ is decreasing in R. Computing the following crossderivative establishes that the output impact of an interest rate reduction is greater for a low-markup firm:

$$
\begin{aligned}
\frac{\partial q}{\partial \xi \partial r} & =\left(\kappa \frac{1-\alpha}{w} \frac{\xi-1}{\xi}\right)^{\frac{(1-\alpha) \xi}{\alpha \xi+(1-\alpha)}}\left(\phi(R)+k_{0}\right)^{\frac{\alpha \xi}{\alpha \xi+(1-\alpha)}}-1\left[\left(\frac{(1-\alpha)}{\alpha \xi+(1-\alpha)}\right)\right. \\
& \left.+\log \left(\kappa \frac{1-\alpha}{w} \frac{\xi-1}{\xi}\right)\left(\frac{(1-\alpha)^{2}}{(\alpha \xi+(1-\alpha))^{2}}\right)+\log \left(\phi(R)+k_{0}\right)\left(\frac{\alpha(1-\alpha)}{(\alpha \xi+(1-\alpha))^{2}}\right)\right] \frac{\alpha \xi}{\alpha \xi+(1-\alpha)} \phi^{\prime}(R) \\
& +\left(\kappa \frac{1-\alpha}{w} \frac{\xi-1}{\xi}\right)^{\frac{(1-\alpha) \xi}{\alpha \xi+(1-\alpha)}}\left(\phi(R)+k_{0}\right)^{\frac{\alpha \xi}{\alpha \xi+(1-\alpha)}}\left[\left(\frac{\alpha(1-\alpha))}{(\alpha \xi+(1-\alpha))^{2}}\right)\left(\frac{\phi^{\prime}(R)}{\left(\phi(R)+k_{0}\right)}\right)\right]<0
\end{aligned}
$$

where this derivative is negative for the same sufficient condition that guarantees that $\frac{\partial q}{\partial \xi}$ is positive in equation.

Lemma 16 If high-and low-markup firms are both financially constrained both ex-ante and ex-post, and have the same initial output level $q^{*}$, then a reduction on the interest rate triggers a larger output response for the low-markup firm $\left(q^{L}>q^{H}\right)$.

Proof The proof follows from Lemma 16 and the fact that $\frac{\partial q}{\partial \xi \partial r}$ in equation 21 is negative. This negative derivative implies that when both firms are constrained, the impact of a decline in the interest rate is stronger for firms with a larger $\xi$, that is, with a lower markup. As a result, if a firm becomes constrained, it will be the low-markup firm, and the impact of the monetary policy on output will be greater for that firm since the financial constraint only depends on $q$. 